\title{
Inhibitory Gating of Basolateral Amygdala Inputs to the Prefrontal Cortex
}

\author{
는aura M. McGarry and Adam G. Carter \\ Center for Neural Science, New York University, New York, New York 10003
}

Interactions between the prefrontal cortex (PFC) and basolateral amygdala (BLA) regulate emotional behaviors. However, a circuit-level understanding of functional connections between these brain regions remains incomplete. The BLA sends prominent glutamatergic projections to the PFC, but the overall influence of these inputs is predominantly inhibitory. Here we combine targeted recordings and optogenetics to examine the synaptic underpinnings of this inhibition in the mouse infralimbic PFC. We find that BLA inputs preferentially target layer 2 corticoamygdala over neighboring corticostriatal neurons. However, these inputs make even stronger connections onto neighboring parvalbumin and somatostatin expressing interneurons. Inhibitory connections from these two populations of interneurons are also much stronger onto corticoamygdala neurons. Consequently, BLA inputs are able to drive robust feedforward inhibition via two parallel interneuron pathways. Moreover, the contributions of these interneurons shift during repetitive activity, due to differences in short-term synaptic dynamics. Thus, parvalbumin interneurons are activated at the start of stimulus trains, whereas somatostatin interneuron activation builds during these trains. Together, these results reveal how the BLA impacts the PFC through a complex interplay of direct excitation and feedforward inhibition. They also highlight the roles of targeted connections onto multiple projection neurons and interneurons in this cortical circuit. Our findings provide a mechanistic understanding for how the BLA can influence the PFC circuit, with important implications for how this circuit participates in the regulation of emotion.

Key words: basolateral amygdala; inhibition; interneuron; prefrontal cortex; projection neuron; synapse

\section{Significance Statement}

The prefrontal cortex (PFC) and basolateral amygdala (BLA) interact to control emotional behaviors. Here we show that BLA inputs elicit direct excitation and feedforward inhibition of layer 2 projection neurons in infralimbic PFC. BLA inputs are much stronger at corticoamygdala neurons compared with nearby corticostriatal neurons. However, these inputs are even more powerful at parvalbumin and somatostatin expressing interneurons. BLA inputs thus activate two parallel inhibitory networks, whose contributions change during repetitive activity. Finally, connections from these interneurons are also more powerful at corticoamygdala neurons compared with corticostriatal neurons. Together, our results demonstrate how the BLA predominantly inhibits the PFC via a complex sequence involving multiple cell-type and input-specific connections.

\section{Introduction}

The prefrontal cortex (PFC) regulates diverse high-level behaviors and is disrupted in mental health disorders (Euston et al., 2012). Interactions between the PFC and basolateral amygdala (BLA) are particularly important for the control of emotion

\footnotetext{
Received March 16, 2016; revised July 11, 2016; accepted July 18, 2016.

Author contributions: L.M.M. and A.G.C. designed research; L.M.M. performed research; L.M.M. analyzed data; L.M.M. and A.G.C. wrote the paper.

This work was supported by National Institutes of Health Grant 1 T32 NS086750 to L.M.M., National Alliance for Research on Schizophrenia and Depression to A.G.C., and National Institutes of Health Grant R01 MH085974 to A.G.C. We thank members of the Carter laboratory for helpful discussions and comments on this manuscript and Matthew Xu-Friedman for help with software.

The authors declare no competing financial interests.

Correspondence should be addressed to Dr. Adam G. Carter, Center for Neural Science, New York University, 4 Washington Place, New York, NY 10003. E-mail: adam.carter@nyu.edu.

DOI:10.1523/JNEUROSCI.0874-16.2016

Copyright $(2016$ the authors $\quad 0270-6474 / 16 / 369391-16 \$ 15.00 / 0$
}

(Sotres-Bayon and Quirk, 2010). These interactions are reciprocal, with the PFC sending projections to the BLA and receiving return connections (Gabbott et al., 2005; Hoover and Vertes, 2007). However, although BLA inputs are glutamatergic, their stimulation in vivo primarily inhibits neural activity in the PFC (Floresco and Tse, 2007). One explanation is that BLA inputs drive robust feedforward inhibition mediated by GABAergic interneurons (Dilgen et al., 2013). However, the ability of BLA inputs to selectively activate different populations of neurons within the PFC has not been established.

BLA axons densely arborize throughout superficial layer 2 (L2) of the PFC, providing glutamatergic input to nearby neurons (Sesack et al., 1989; Little and Carter, 2012). There are many populations of projection neurons, which project to distinct targets and have unique roles (Gabbott et al., 2005). Projection neurons have been mostly studied in deep layers, where they 
send long-range projections to cortical and subcortical targets (Morishima et al., 2011; Otsuka and Kawaguchi, 2011). Corticoamygdala (CA) neurons are prominent in superficial layers, intermingled with corticostriatal (CS) neurons (Hirai et al., 2012). BLA inputs selectively innervate CA neurons, establishing a mechanism for reciprocal interactions (Little and Carter, 2013). However, the overall influence of BLA inputs could be inhibitory if connections are stronger onto local GABAergic interneurons.

The PFC also possesses a variety of GABAergic interneurons, which have distinct morphological and physiological properties, including parvalbumin (PV) and somatostatin (SOM) expressing interneurons (Kawaguchi and Kubota, 1997, 1998; Marlin and Carter, 2014). In principle, BLA inputs are well positioned to synapse onto these interneurons to drive local inhibition in the circuit. In deeper layers, interneurons have been found to make preferential connections onto different types of projection neurons. For example, inhibitory contacts from PV interneurons are stronger onto corticothalamic than corticocortical neurons in the PFC (Lee et al., 2014), and stronger onto corticocortical than corticocollicular neurons in the auditory cortex (Rock and Apicella, 2015). However, whether PV and other classes of interneurons also make targeted connections onto projection neurons in the superficial PFC has not been tested.

The influence of the BLA on the PFC ultimately depends on the sequence in which different cell types are activated. Preferential activation of interneurons before pyramidal neurons leads to feedforward inhibition, whereas activation of pyramidal neurons before interneurons can evoke feedback inhibition (Isaacson and Scanziani, 2011). In cortical circuits, PV and SOM interneurons are often found to mediate feedforward and feedback inhibition, respectively (Gabernet et al., 2005; Sun et al., 2006; Kapfer et al., 2007; Silberberg and Markram, 2007; Cruikshank et al., 2010). In the PFC, thalamic inputs preferentially activate PV interneurons to evoke robust feedforward inhibition (Delevich et al., 2015). However, in some cases, long-range inputs to the cortex have also been shown to activate SOM interneurons (Porter et al., 2001; Tan et al., 2008).

Here we examine how inputs from the BLA generate feedforward inhibition in the mouse infralimbic PFC. We find that both excitatory inputs from the BLA and inhibitory inputs from local interneurons are stronger onto CA neurons than nearby CS neurons. We then establish that BLA afferents make monosynaptic connections onto both PV and SOM interneurons. We show that these connections have unique properties depending on the target cell types, with strongest BLA inputs onto PV interneurons and facilitating BLA inputs onto SOM interneurons. Finally, we demonstrate that the BLA activates both populations of interneurons before CA neurons, creating parallel pathways of feedforward inhibition. Together, our findings reveal how BLA inputs selectively engage multiple populations of neurons to elicit robust feedforward inhibition in the PFC.

\section{Materials and Methods}

Neurons were studied in acute slices of the infralimbic PFC prepared from P42-P56 C57 BL/6J, PV-Cre (Hippenmeyer et al., 2005) or SOMCre (Taniguchi et al., 2011) mice. All physiology experiments used male mice, and some anatomy experiments also used female mice. For some anatomy experiments, $\mathrm{PV}$-Cre and SOM-Cre mice were bred with Ai9 Cre-dependent reporter mice (Madisen et al., 2010). All procedures followed guidelines approved by the New York University animal welfare committee.

Stereotaxic injections. To target different neurons and synaptic connections, stereotaxic injections were performed on P28-P36 mice, as previ- ously described (Little and Carter, 2012). Injection site coordinates were relative to bregma (mediolateral axis, dorsoventral axis, and rostrocaudal axis: $\mathrm{PFC}=-0.3 \mathrm{~mm},-2.3 \mathrm{~mm}$, and $2.1 \mathrm{~mm} ; \mathrm{NAc}=-2.6 \mathrm{~mm},-4.6$ $\mathrm{mm}, 1.7 \mathrm{~mm}$ at $13^{\circ}$; BLA $=-3 \mathrm{~mm},-5 \mathrm{~mm}$, and $-1.2 \mathrm{~mm}$ ). For anterograde tracing, $184-230 \mathrm{nl}$ of virus was injected (AAV2/1-hSynGFP or AAV2/1-CB7-mCherry; UPenn Vector Core). For retrograde labeling, $184-230 \mathrm{nl}$ of a $0.2 \%$ dilution of AlexaFluor-conjugated cholera toxin subunit B (CTB-Alexa-488 or CTB-Alexa-647; Invitrogen) or undiluted retrobeads (green or red; Lumafluor) was injected into the NAc or BLA. To eliminate recording biases, the color of beads across experiments used to label each projection neuron class was alternated. However, for clarity, figure schematics show CA neurons labeled with green beads and CS neurons labeled with red beads. For combined retrograde labeling and optogenetics, 345-460 $\mathrm{nl}$ of a 2:1 mixture of virus (AAV2/ 1-hSyn-hChR2-eYFP; UPenn Vector Core) and either red or green retrobeads was injected into the BLA (Mao et al., 2011; Little and Carter, 2013). For labeling of interneurons, $184-230 \mathrm{nl}$ of virus (AAV2/1-CAGFLEX-tdTomato; UPenn Vector Core) was injected into the PFC of $P V$ Cre or SOM-Cre animals. For monosynaptic retrograde tracing from PV or SOM interneurons, $500-800 \mathrm{nl}$ of helper viruses (AAV2/1-EF1aFLEX-TVA-mCherry and AAV2/1-CA-FLEX-glycoprotein; UNC Vector Core) was injected into the PFC, then 2 weeks later SAD $\Delta$ GGFP(EnvA) (Salk Vector Core) was injected into the PFC of PV-Cre or SOM-Cre animals. Animals were killed 7-10 d after rabies virus injections. For optogenetic activation of interneurons, $184 \mathrm{nl}$ of virus (AAV2/ 1-EF1a-DIO-hChR2-eYFP; UPenn Vector Core) was injected into the PFC of either PV-Cre or SOM-Cre animals. After all injections, animals were returned to their home cages for $2-3$ weeks before being used for experiments.

Slice preparation. Mice were anesthetized with an intraperitoneal injection of a lethal dose of ketamine/xylazine. After anesthesia, mice were perfused intracardially with an ice-cold solution containing the following (in mM): 65 sucrose, $76 \mathrm{NaCl}, 25 \mathrm{NaHCO}_{3}, 1.4 \mathrm{NaH}_{2} \mathrm{PO}_{4}, 25$ glucose, 2.5 $\mathrm{KCl}, 7 \mathrm{MgCl}_{2}, 0.4 \mathrm{Na}$-ascorbate, and $2 \mathrm{Na}$-pyruvate (bubbled with $95 \%$ $\mathrm{O}_{2} / 5 \% \mathrm{CO}_{2}$ ). Coronal sections ( $300 \mu \mathrm{m}$ thick) were cut in this solution and transferred to ACSF containing the following (in $\mathrm{mM}$ ): $120 \mathrm{NaCl}, 25$ $\mathrm{NaHCO}_{3}, 1.4 \mathrm{NaH}_{2} \mathrm{PO}_{4}, 21$ glucose, $2.5 \mathrm{KCl}, 2 \mathrm{CaCl}_{2}, 1 \mathrm{MgCl}_{2}, 0.4$ $\mathrm{Na}$-ascorbate, and $2 \mathrm{Na}$-pyruvate (bubbled with $95 \% \mathrm{O}_{2} / 5 \% \mathrm{CO}_{2}$ ). Slices were recovered for $30 \mathrm{~min}$ at $34^{\circ} \mathrm{C}$ and stored for at least $30 \mathrm{~min}$ at $24^{\circ} \mathrm{C}$. All experiments were conducted at $30^{\circ} \mathrm{C}-34^{\circ} \mathrm{C}$. In many experiments, 1 $\mu \mathrm{M}$ TTX was included to block action potentials (APs), and $0.1 \mathrm{~mm} 4-\mathrm{AP}$ and $4 \mathrm{~mm}$ external $\mathrm{Ca}^{2+}$ to restore presynaptic glutamate release. In some experiments, one or more of the following were bath-applied: 10 $\mu \mathrm{M}$ NBQX to block AMPA-Rs, $10 \mu \mathrm{M}$ CPP to block NMDA-Rs, $10 \mu \mathrm{M}$ D-serine to allow NMDA-R activation, $10 \mu \mathrm{M}$ gabazine to block $\mathrm{GABA}_{\mathrm{A}^{-}}$ Rs, $5 \mu \mathrm{M}$ CGP to block $\mathrm{GABA}_{\mathrm{B}}$-Rs. All chemicals were from Sigma or Tocris Bioscience.

Electrophysiology. Targeted whole-cell recordings were made from projection neurons and interneurons located in a band ( $\sim 30 \mu \mathrm{m}$ thick) near the L1/L2 border, $\sim 180 \mu \mathrm{m}$ from the pial surface, using infrareddifferential interference contrast. CA and CS neurons were identified by the presence of retrobeads. PV and SOM interneurons were identified by the expression of eYFP or tdTomato. Recording order was alternated across experiments for the two cell types in each pair of compared neurons. For voltage-clamp experiments, borosilicate pipettes (3-5 $\mathrm{m} \Omega$ ) were filled with the following (in mM): 135 Cs-gluconate, 10 HEPES, 10 Na-phosphocreatine, $4 \mathrm{Mg}_{2}$-ATP, $0.4 \mathrm{NaGTP}, 10 \mathrm{TEA}, 2 \mathrm{QX}-314$, and 10 EGTA, pH 7.3 with $\mathrm{CsOH}$ (290-295 mOsm). For current-clamp recordings, borosilicate pipettes $(3-5 \mathrm{M} \Omega$ ) were filled with the following (in $\mathrm{mm}$ ): $135 \mathrm{~K}$-gluconate, $7 \mathrm{KCl}, 10 \mathrm{HEPES}, 10 \mathrm{Na}$-phosphocreatine, $4 \mathrm{Mg}_{2}{ }^{-}$ ATP, 0.4 NaGTP, and 0.5 EGTA, pH 7.3 with KOH (290-295 mOsm). In both cases, $30 \mu \mathrm{M}$ AlexaFluor-594 or -488 were added to visualize neuronal morphology with 2-photon microscopy. Physiology data were collected with a Multiclamp 700B amplifier. Signals were sampled at $10 \mathrm{kHz}$ and filtered at $5 \mathrm{kHz}$ for current-clamp recordings and at $2 \mathrm{kHz}$ for voltage-clamp recordings. Series resistance was $<25 \mathrm{~m} \Omega$ and not compensated.

Optogenetics. Glutamate release was triggered by activating channelrhodopsin-2 (ChR2) present in the presynaptic terminals of BLA in- 
puts to the PFC, as previously described (Little and Carter, 2012). GABA release was triggered by activating ChR2 in PV or SOM interneurons within the PFC, as previously described (Marlin and Carter, 2014). To avoid any potential recording biases, nearby CA::CS pairs, CA::PV pairs, or CA::SOM pairs were recorded in alternating order. ChR2 was activated with 1-8 ms pulses of $473 \mathrm{~nm}$ light from a light-emitting diode (LED) through a $60 \times$ objective with an average power of $\sim 3 \mathrm{~mW}$. The objective was always centered over the pair of cells.

Two-photon microscopy. Two-photon imaging was performed on a custom microscope, as previously described (Chalifoux and Carter, 2010). Briefly, a titanium:sapphire laser (Coherent) tuned to $810 \mathrm{~nm}$ was used to excite AlexaFluor-594 or -488 to image dendrite morphology. Imaging was performed with a $60 \times, 1.0$ numerical aperture objective (Olympus).

Histology. Mice were anesthetized and perfused intracardially with $0.01 \mathrm{M}$ PBS and $4 \%$ PFA. Brains were stored in $4 \%$ PFA for $12-18 \mathrm{~h}$ at $4^{\circ} \mathrm{C}$ before being transferred to $0.01 \mathrm{M}$ PBS. Slices were cut on a VT-1000S vibratome (Leica) at 50-70 $\mu \mathrm{m}$ thickness and placed on gel-coated glass slides. ProLong Gold anti-fade reagent with DAPI (Invitrogen) was applied to the surface of the slices, which were then covered with a glass coverslip. Fluorescent images were taken on an Olympus VS120 microscope. Images were acquired with a $10 \times$ objective, except for images for CA and CS localization, which were acquired with a $40 \times$ objective.

Data analysis. Imaging and physiology data were acquired using $\mathrm{Na}-$ tional Instruments boards and custom software written in MATLAB (The MathWorks). For EPSC current injection experiments, physiology data were collected using Igor Pro (Wavemetrics) running mafPC (courtesy of Matthew Xu-Friedman). Image processing and analysis were performed in National Institutes of Health ImageJ. Physiology analysis was performed in Igor Pro (Wavemetrics). Morphological analysis was conducted in NeuronStudio (Wearne et al., 2005).

For analysis of two-photon image stacks, all visible dendrites of each Alexa dye-filled neuron were reconstructed in NeuronStudio to quantify dendritic length and branch points, as previously described (Little and Carter, 2013). For axon distribution analysis, fluorescence intensity profiles were averaged across 3 slices per animal in $300 \mu \mathrm{m} \times 1000 \mu \mathrm{m}$ of infralimbic PFC, with background subtracted from an unlabeled part of the slice and normalized to the maximum within each slice. For colocalization, cell counting was performed in ImageJ on a 3-color image of retrogradely labeled CA and CS neurons and DAPI labeling. CTB-labeled cell bodies were manually counted in regions $300 \times 1000 \mu \mathrm{m}$ in infralimbic PFC across 3 slices per animal.

Intrinsic properties were determined as follows. Input resistance was calculated from the steady-state voltage during a $-50 \mathrm{pA}, 500 \mathrm{~ms}$ current step. Voltage sag was also calculated from this response as $\left(\mathrm{V}_{\text {sag }}-\mathrm{V}_{\mathrm{ss}}\right) /$ $\left(\mathrm{V}_{\text {sag }}-\mathrm{V}_{\text {baseline }}\right)$, where $\mathrm{V}_{\text {sag }}$ is the average over a $1 \mathrm{~ms}$ window around the minimum, $\mathrm{V}_{\mathrm{ss}}$ is the average of the last $50 \mathrm{~ms}$, and $\mathrm{V}_{\text {baseline }}$ is the average of the $50 \mathrm{~ms}$ preceding the current injection. Adaptation was calculated as the ratio of the first and last interspike intervals, such that a value of 1 indicates no adaptation and values $<1$ indicate lengthening of the interspike interval.

EPSC and IPSC amplitudes were calculated as the average over a $1 \mathrm{~ms}$ window around the peak. NMDA-R EPSCs were calculated as the peak of the $40 \mathrm{mV}$ EPSC at $50 \mathrm{~ms}$ after onset, at which time the AMPA-R component has decayed. Decay time was calculated by fitting an exponential from the peak. For experiments with sequential recordings, summary comparisons show all data points and mean $\pm \mathrm{SE}$ of the amplitude, and all data points and mean \pm SE of the ratios. Average EPSCs and IPSCs are shown as mean \pm SE of all recorded pairs for each experiment. Currentclamp recordings are shown as representative examples, with individual traces for suprathreshold responses and average for subthreshold responses. Statistical comparisons of measured values between 2 groups were performed using the Mann-Whitney test if data were not acquired in sequential pairs, or using the Wilcoxon Signed-Rank test if data were acquired in sequential pairs. Two-tailed $p$ values $<0.05$ are considered significant.

\section{Results}

Distinct populations of $\mathrm{L} 2$ projection neurons in the infralimbic PFC

We examined how glutamatergic inputs from the BLA engage different populations of projection neurons and GABAergic interneurons in L2 of the infralimbic PFC. We first characterized the laminar distribution, dendritic morphology, and intrinsic physiology of CA and CS neurons. We injected fluorescent retrograde tracers into the BLA and nucleus accumbens (NAc) of the same animals (Fig. 1A), and found that CA and CS neurons are concentrated in the superficial layers (Fig. 1B). Importantly, there was minimal overlap between these neurons $(4.6 \%$ colabeled cells of all labeled cells; $n=3$ mice, 3 slices per mouse), with no overlap in the first $200 \mu \mathrm{m}$ from the pia where we performed our experiments, indicating two distinct classes of projection neurons.

We next filled neighboring CA and CS neurons with fluorescent dyes and imaged their morphology with 2-photon microscopy. The two cell types had compact dendrites branching in L1 and L2 (Fig. 1C), with indistinguishable properties as determined by dendritic length $(\mathrm{CA}=3.3 \pm 0.6 \mathrm{~mm}, n=7$; $\mathrm{CS}=2.5 \pm 0.3 \mathrm{~mm}, n=8 ; p=0.13)$ and number of branch points $(\mathrm{CA}=23.2 \pm 4.3, n=7$; $\mathrm{CS}=19.0 \pm 1.7, n=8 ; p=$ 0.18 ). In current-clamp recordings, we determined the passive and firing properties of these cell types, finding they were very similar, with regular spiking (Fig. 1D) and identical F/I curves (Fig. 1E). We also observed comparable resting membrane potentials $(\mathrm{CA}=-76.6 \pm 1.6 \mathrm{mV}, n=8 ; \mathrm{CS}=-73.2 \pm 1.5$ $\mathrm{mV}, n=9 ; p=0.1)$, input resistances $(\mathrm{CA}=163 \pm 18 \mathrm{M} \Omega$, $n=8 ; \mathrm{CS}=191 \pm 29 \mathrm{M} \Omega, n=9 ; p=0.56)$, and firing adaptation $(\mathrm{CA}=0.38 \pm 0.07, n=8 ; \mathrm{CS}=0.47 \pm 0.04, n=$ $9 ; p=0.1$ ), with neither cell type displaying a hyperpolarizing voltage sag $(\mathrm{CA}=1.9 \pm 0.3 \%, n=8 ; \mathrm{CS}=1.9 \pm 0.7 \%, n=9$; $p=0.6)($ Fig. $1 F)$. Together, these findings suggest that CA and CS neurons may have similar abilities to sample and process long-range connections from the BLA.

\section{BLA-evoked sequences of excitation and inhibition}

Having established the properties of CA and CS neurons, we assessed the organization of connections from the BLA. We injected AAVmCherry into the BLA (Fig. 2A) and observed fluorescent axons concentrated in L2 of the PFC (Fig. 2B). Interestingly, the maximum of this axon distribution overlaps with the dendrites of both CA and CS neurons, suggesting BLA inputs are positioned to contact these neurons.

We then determined whether BLA inputs trigger excitatory or inhibitory synaptic responses at CA and CS neurons in the PFC. We injected both AAV-ChR2-eYFP and either green or red retrobeads in the BLA, and the opposite color retrobeads in the NAc (Fig. 2C). After waiting for expression and transport, we prepared acute brain slices of PFC, which severs BLA axons but preserves their terminals (Petreanu et al., 2007). We stimulated BLA inputs by activating ChR2 in the presynaptic axons using a wide-field LED (473 nm) (Little and Carter, 2012). We performed sequential voltage-clamp recordings of light-evoked AMPA-R EPSCs at $-70 \mathrm{mV}$ and $\mathrm{GABA}_{\mathrm{A}}-\mathrm{R}$ IPSCs at $10 \mathrm{mV}$. To eliminate any recording biases, we recorded from neighboring CA and CS neurons at the same depth in the slice for paired comparisons. This approach allows us to directly compare synaptic responses between these neurons, and control for any variability in responses between slices or animals (Little and Carter, 2013; MacAskill et al., 2014).

We found that optogenetic stimulation of BLA inputs evoked EPSCs and IPSCs at CA and CS neurons (Fig. 2D). In both cell 
A

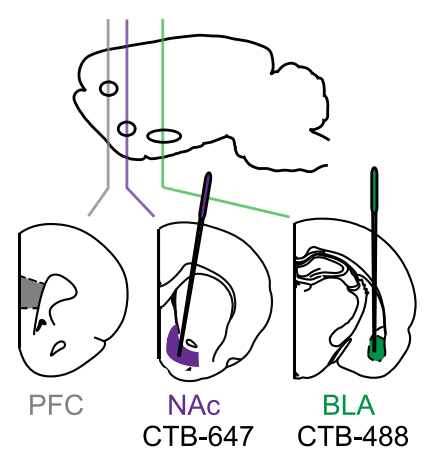

B

C

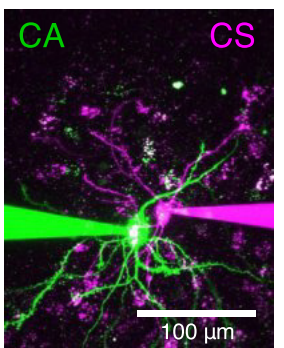

D
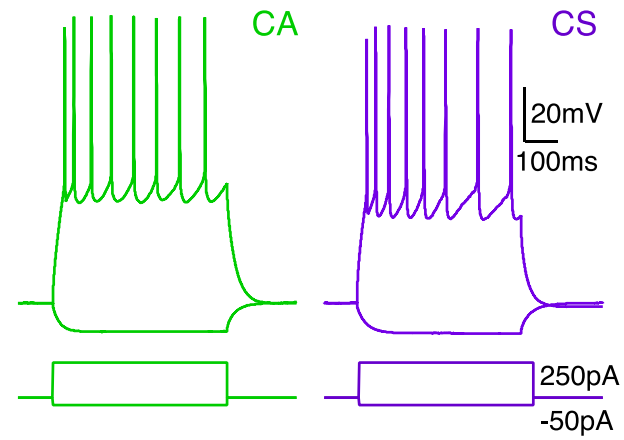

Cells per $25 \mu \mathrm{m}$
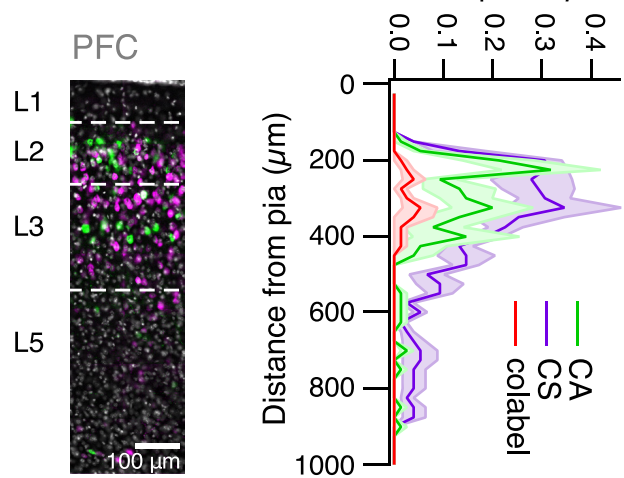

E
F

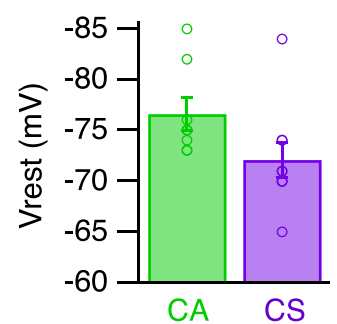

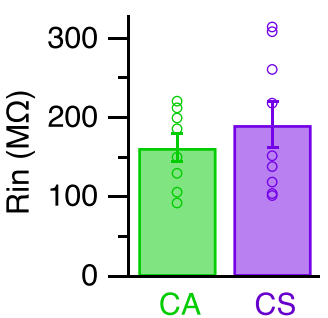

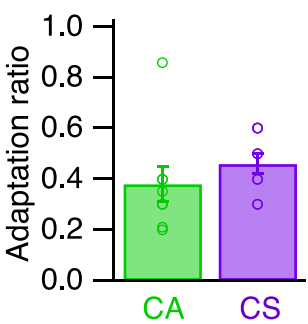

Figure 1. Properties of CA and CS neurons in the infralimbic PFC. A, Schematic of injecting (TB-Alexa-647 into the NAc and CTB-Alexa-488 into the BLA of wild-type mice, to label neurons in the infralimbic PFC. Cardinal axes pictured to right for injection schematics apply to all figures. $B$, Left, CA (green) and CS (purple) neurons in the PFC, with DAPI staining in gray. White lines indicate laminar borders. Right, Quantification of CA, CS, and colabeled (red) cells in the PFC. C, Two-photon image of neighboring CA and CS neurons. D, AP firing and hyperpolarization in response to 250 $\mathrm{pA}$ and $-50 \mathrm{pA}$ current injections in the presence of synaptic blockers. $\boldsymbol{E}$, Summary of AP firing over a range of current injections. $\boldsymbol{F}$, Summary of resting membrane potential, input resistance, adaptation ratio, and voltage sag.

types, the onset of the IPSC always lagged the EPSC (EPSC to IPSC latency: $\mathrm{CA}=2.8 \pm 0.1 \mathrm{~ms} ; \mathrm{CS}=3.0 \pm 0.2 \mathrm{~ms} ; n=7$ pairs). Blocking glutamatergic transmission with NBQX abolished both EPSCs and IPSCs ( + NBQX residual EPSC $=0.4 \%$; residual IPSC $=1.7 \% ; n=2$ CA and 2 CS neurons), indicating that BLA inputs are glutamatergic, and delayed inhibition is disynaptic. Interestingly, both EPSCs and IPSCs were much larger at CA than CS neurons (CS/CA amplitude ratio: $\mathrm{EPSC}=0.38 \pm$ $0.04, p=0.02$; IPSC $=0.32 \pm 0.07, p=0.02 ; n=7$ pairs) (Fig. $2 E$ ), with no difference in decays (CS/CA decay ratio: EPSC $=$ $1.1 \pm 0.04, p=0.1 ;$ IPSC $=1.17 \pm 0.21, p=1 ; n=7$ pairs $)$. Because of a similar bias of excitation and inhibition, the overall EPSC/IPSC amplitude ratio was equivalent at CA and CS neurons (Fig. $2 F$ ). Together, these results indicate that excitation and inhibition are balanced at these cell types, with stronger excitation and inhibition onto CA neurons.
Cell-type-specific excitatory connections from the BLA

The larger EPSCs at CA neurons could reflect the preferential targeting of this cell type by axons from the BLA. Previous studies in the prelimbic PFC suggest that BLA inputs make more connections onto CA neurons compared with corticocortical neurons (Little and Carter, 2013). To explore whether similar targeting occurs in the infralimbic PFC, we first compared the relative contributions of AMPA-Rs and NMDA-Rs at CA and CS neurons. In slices with labeled CA and CS neurons and ChR2 in BLA axons (Fig. $3 A$ ), we recorded at $-70 \mathrm{mV}$ and $40 \mathrm{mV}$ to measure AMPA-R and NMDA-R EPSCs, respectively (Fig. 3B). To isolate monosynaptic connections, we included TTX $(1 \mu \mathrm{M})$ to block action potentials, and 4-AP $(100 \mu \mathrm{M})$ and elevated external $\mathrm{Ca}^{2+}$ (4 mM) to restore glutamate release (Petreanu et al., 2009; Little and Carter, 2012). We found that both AMPA-R and NMDA-R EPSCs were larger at CA neurons (CS/CA amplitude ratio: 
A

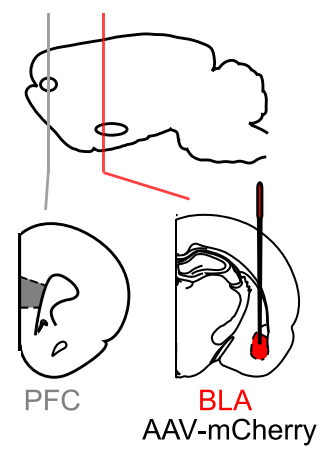

B

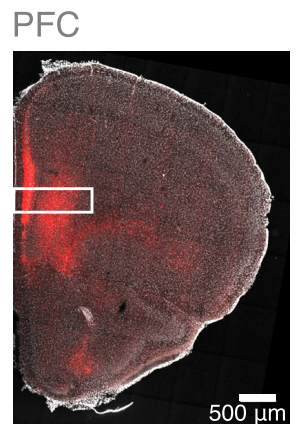

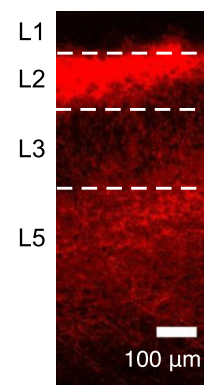

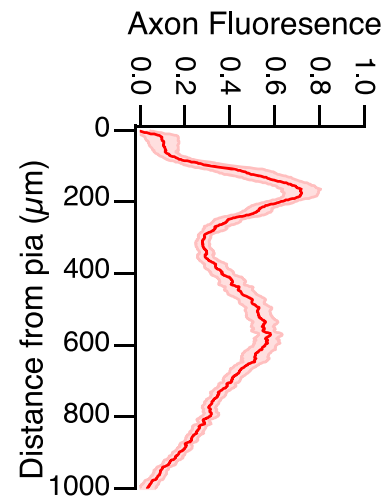

C

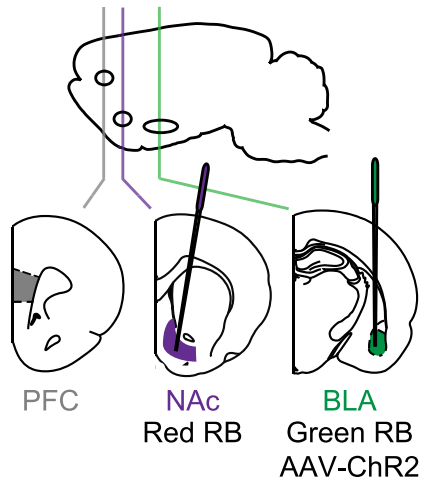

D

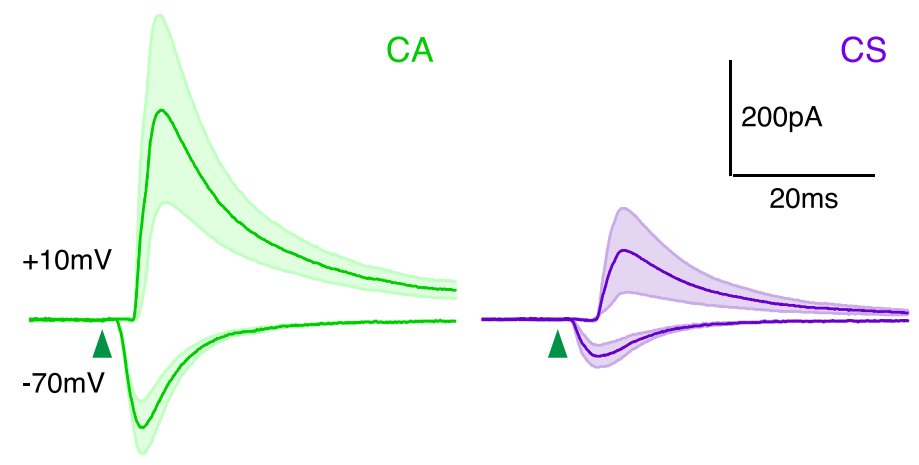

E
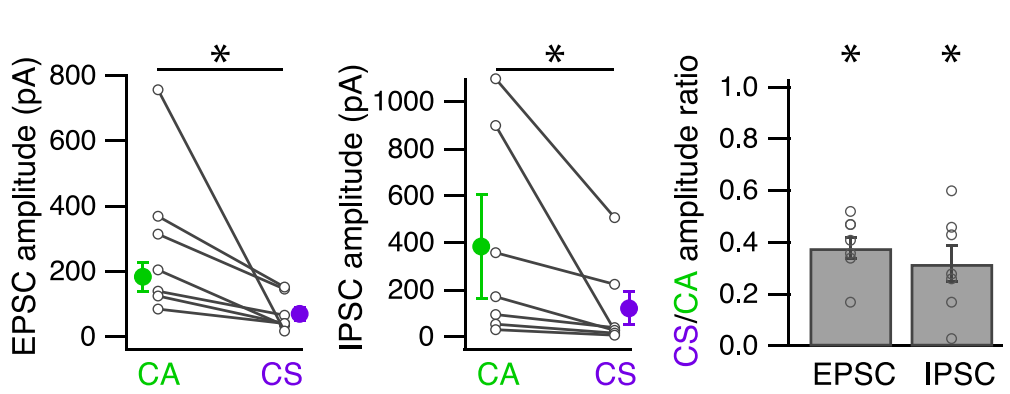

F

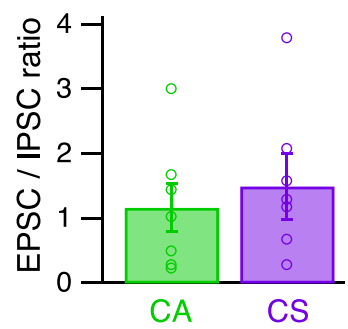

Figure 2. BLA-evoked excitation and inhibition. $A$, Schematic of injecting AAV-mCherry into the BLA of wild-type mice, to label BLA axons in the infralimbic PFC. $B$, Left, BLA axons in a coronal section. White box indicates analyzed portion of PFC. Middle, BLA axons in the PFC. White lines indicate laminar borders. Right, Distribution of BLA axons in the PFC, with fluorescence normalized to an unlabeled portion of the slice. C, Schematic of injecting red retrobeads into the NAc and green retrobeads and AAV-ChR2-eYFP into the BLA of wild-type mice, to label CS and CA neurons and express ChR2 in BLA axons in the infralimbic PFC. D, Average BLA-evoked AMPA-REPSCs at $-70 \mathrm{mV}$ and GABA $A_{A}-R I P S C s$ at $10 \mathrm{mV}$ in the presence of CPP. Green arrowhead indicates time of LED pulse. $\boldsymbol{E}$, Summary of amplitudes of BLA-evoked EPSCs (left) and IPSCS (middle) at CA and CS neurons. Lines connect pairs of recorded neurons. Summary of CS/CA amplitude ratio for EPSCS and IPSCS (right). $\boldsymbol{F}$, Summary of EPSC/IPSC amplitude ratio at CA and CS neurons. ${ }^{*} p<0.05$.

AMPA-R EPSC $=0.49 \pm 0.09, p=0.01 ;$ NMDA-R EPSC $=$ $0.55 \pm 0.07, p=0.01 ; n=8$ pairs) (Fig. $3 C$ ). However, the decay was again similar for both of these synaptic responses (CS/CA decay ratio: AMPA-R ESPC $=1.15 \pm 0.14, p=0.44$; NMDA-R EPSCs $=1.19 \pm 0.13, p=0.78, n=8$ pairs). Because both AMPA-R and NMDA-R EPSCs were larger at CA neurons, the overall AMPA/NMDA ratio was also equivalent at the two cell types $(\mathrm{CA}=4.9 \pm 0.9 ; \mathrm{CS}=4.3 \pm 0.8 ; n=8$ pairs; $p=0.4)$ (Fig. 3D).

Presynaptic properties can also influence synaptic strength, which is often reflected in short-term dynamics (Zucker and Regehr, 2002). Therefore, we next compared synaptic responses evoked by repetitive stimulation of BLA inputs at CA and CS neurons. For these experiments, we excluded TTX and 4-AP to allow presynaptic action potentials, and adjusted LED intensity to avoid polysynaptic activity. In voltage-clamp recordings, we found that trains of BLA inputs ( 5 pulses, $20 \mathrm{~Hz}$ ) elicited robust
AMPA-R EPSCs at $-70 \mathrm{mV}$ (Fig. 3E). All EPSCs were larger at CA neurons, yielding a constant CS/CA amplitude ratio throughout ( $n=7$ pairs) (Fig. $3 F$ ). Moreover, BLA synapses were depressing at CA and CS neurons, with a similar paired-pulse ratio (PPR) across all pulses ( $n=7$ pairs) (Fig. $3 F)$. These results indicate short-term dynamics are similar at CA and CS neurons, with robust depression at both cell types. Together, these findings of larger EPSCs at CA neurons but similar postsynaptic and presynaptic properties are consistent with more connections onto CA neurons (Little and Carter, 2013).

\section{Cell-type-specific inhibition from local interneurons}

Having examined the stronger excitation onto CA neurons, we returned to the possibility of preferential inhibition of these neurons. We hypothesized that larger disynaptic IPSCs resulted from stronger inhibitory connections onto CA neurons compared with CS neurons. We assessed connections from PV and SOM 
A

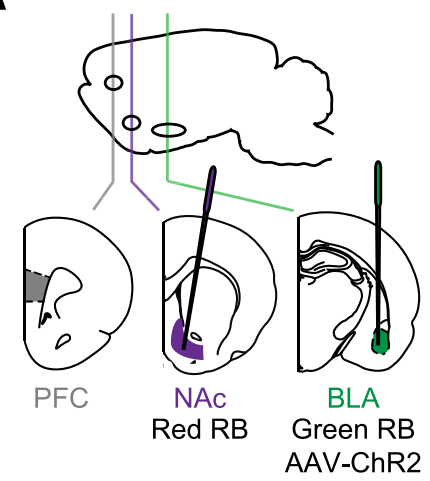

B

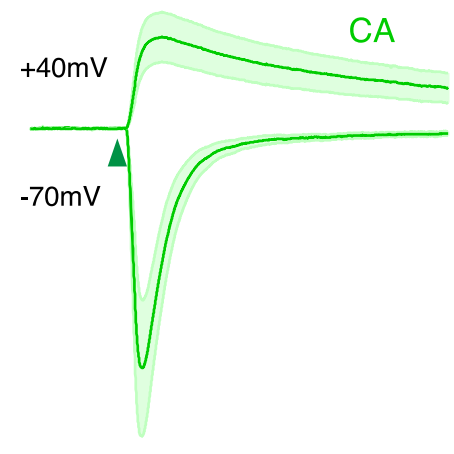

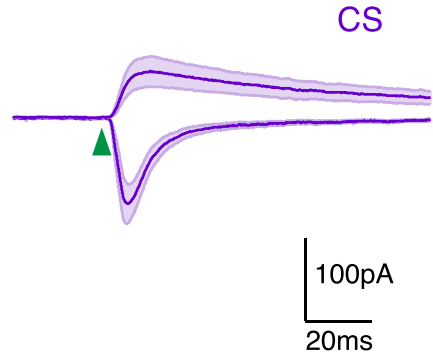

CS

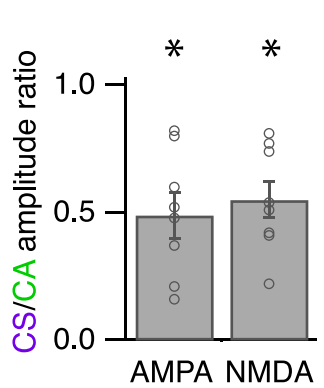

D

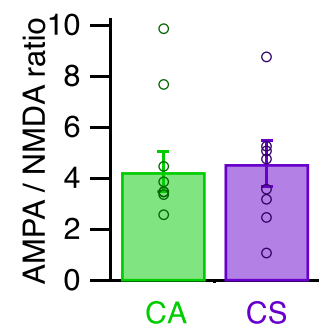

C
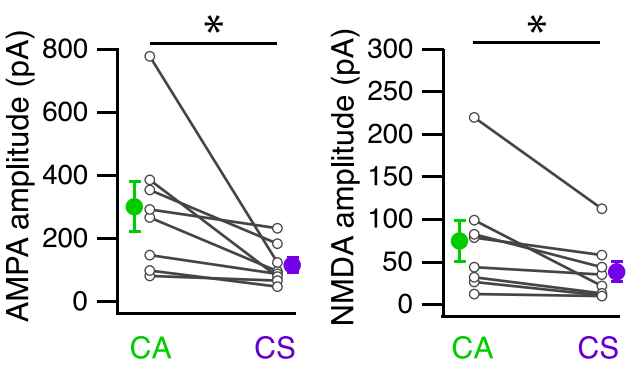

E

F
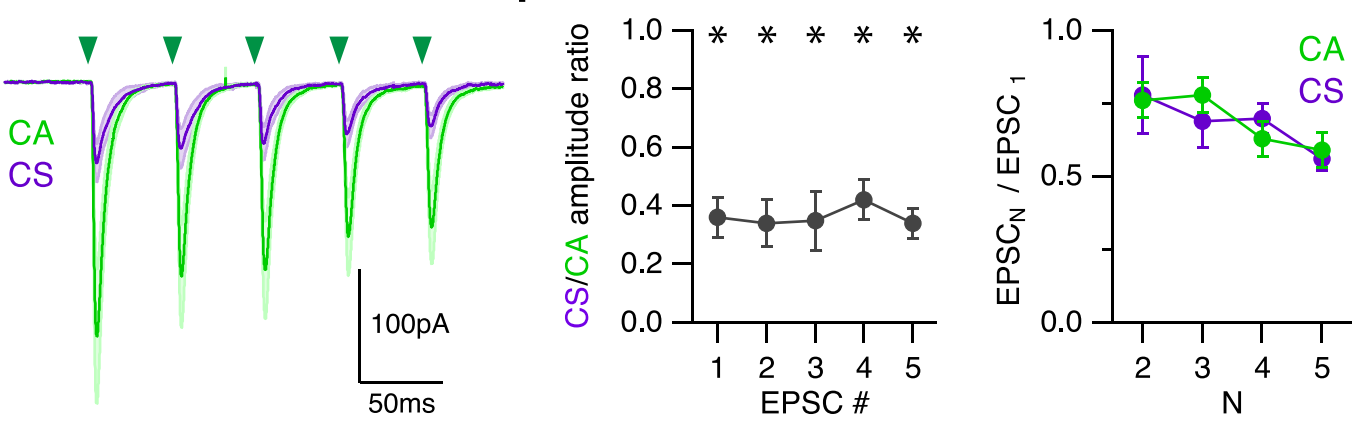

Figure 3. BLA inputs are stronger onto CA neurons. $A$, Schematic of injecting red retrobeads into the NAc and green retrobeads and AAV-ChR2-eYFP into the BLA of wild-type mice, to label CA and CS neurons and express ChR2 in BLA axons in the infralimbic PFC. B, Average BLA-evoked AMPA-R EPSCs at $-70 \mathrm{mV}$ and NMDA-R EPSCs at $40 \mathrm{mV}$ in the presence of TTX, 4-AP, high Ca ${ }^{2+}$, and gabazine. Green arrowhead indicates time of LED pulse. C, Summary of amplitudes of BLA-evoked AMPA (left) and NMDA (middle) EPSCS at CA and CS neurons. Lines connect pairs of recorded neurons. Summary of CS/CA amplitude ratio (right). D, Summary of AMPA/NMDA ratio at CA and CS neurons. $E$, Average AMPA-R EPSCS evoked by trains of BLA inputs (5 pulses at $20 \mathrm{~Hz}$ ) in the presence of CPP and gabazine. Green arrowheads indicate timing of LED pulses. $F$, Summary of CS/CA amplitude ratio (left) and PPR (right) during trains. ${ }^{*} p<0.05$.

interneurons, two main classes of cortical GABAergic interneurons. We first used transgenic mice (Hippenmeyer et al., 2005; Taniguchi et al., 2011) to characterize these interneurons in infralimbic PFC. We found PV interneurons in all layers except L1, although at a lower density than other cortical areas (Fig. $4 A$ ). In contrast, we found SOM interneurons in all layers, with their axons particularly prominent in L1 (Fig. 4B). In current-clamp recordings from labeled neurons in $\mathrm{L} 2$ (Fig. 4C), PV interneurons were fast spiking, whereas SOM interneurons were regular spiking (Fig. 4D). SOM interneurons also exhibited more depolarized resting membrane potentials $(\mathrm{PV}=-68.9 \pm 1.2 \mathrm{mV}, n=8$; $\mathrm{SOM}=-64.2 \pm 0.7 \mathrm{mV}, n=11 ; p=0.005)$ and higher input resistance $(\mathrm{PV}=132 \pm 11 \mathrm{M} \Omega, n=8 ; \mathrm{SOM}=308 \pm 21 \mathrm{M} \Omega, n=$ $11 ; p=0.0003$ ) (Fig. $4 E$ ). In principle, these properties could allow SOM interneurons to be activated more readily than PV interneurons by excitatory inputs. Finally, SOM interneurons exhibited more prominent spike frequency adaptation $(\mathrm{PV}=$ $0.93 \pm 0.06, n=8 ; \mathrm{SOM}=0.55 \pm 0.05, n=11 ; p=0.002)$ and voltage sag $(\mathrm{PV}=3.2 \pm 0.6 \%, n=8 ; \mathrm{SOM}=12.4 \pm 1.6 \%, n=$ $11 ; p=0.002$ ) (Fig. $4 E$ ). These results are consistent with previ- ous studies of these two populations of interneurons in both the PFC and other parts of cortex (Kawaguchi and Kubota, 1997, 1998; Markram et al., 2004).

We next tested for differential inhibition by combining conditional optogenetics with cell-type-specific recordings. We retrogradely labeled CA and CS neurons, and injected AAV-DIOChR2-eYFP into the PFC of SOM-Cre or PV-Cre mice (Fig. 5A). We first assessed our ability to drive light-evoked action potentials in PV and SOM interneurons using current-clamp recordings from labeled interneurons while activating ChR2 with a series of light pulses in the presence of synaptic blockers. We found reliable firing of action potentials in PV $(n=8)$ and SOM $(n=5)$ interneurons across a wide range of LED durations, often firing multiple action potentials at longer LED durations (Fig. $5 B, C)$.

We then examined synaptic responses by activating ChR2 with wide-field illumination and recording from neighboring CA and CS neurons. We found that activation of PV or SOM interneurons elicited robust $\mathrm{GABA}_{\mathrm{A}}-\mathrm{R}$ IPSCs in both cell types (Fig. $5 D, F$ ), but responses were always much larger at CA neu- 
A

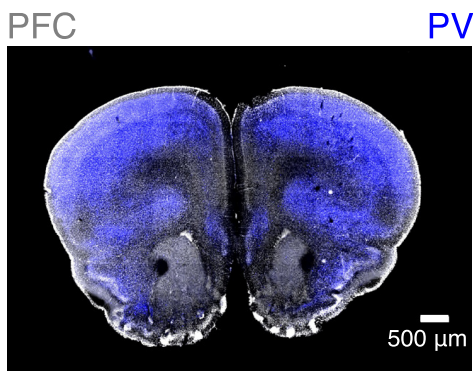

B

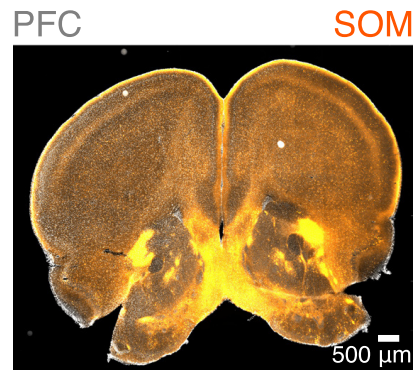

L1

L2

L3

L5

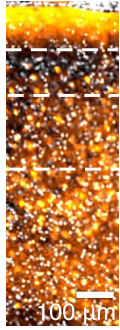

C

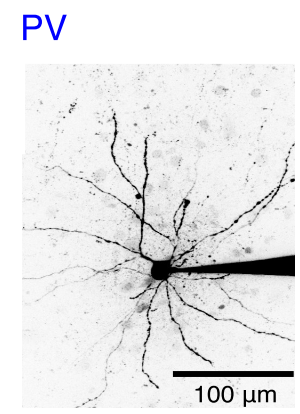

\section{SOM}

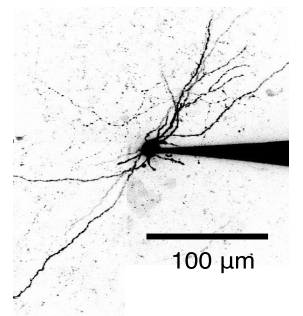

D
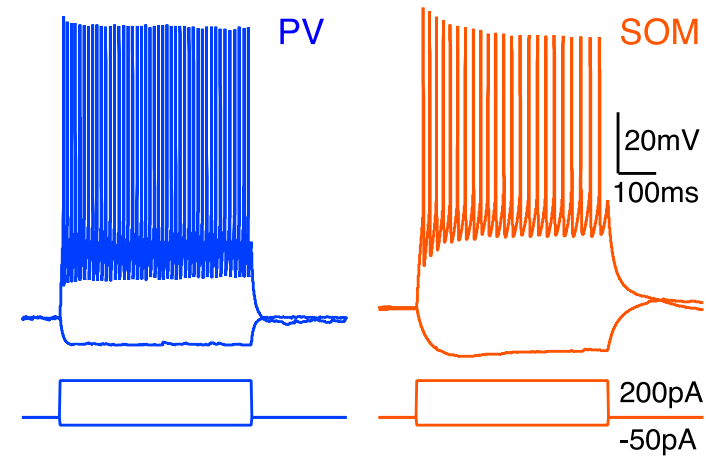

E
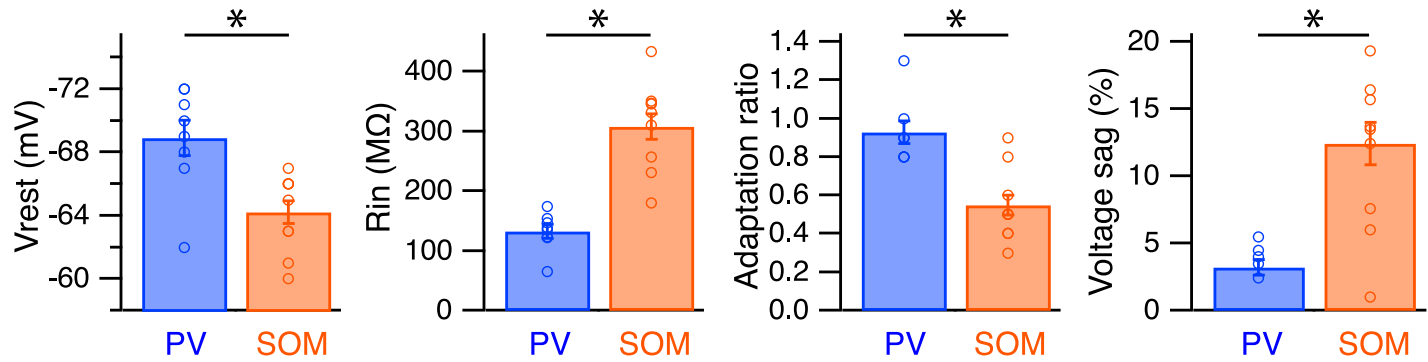

Figure 4. PV and SOM interneurons in the infralimbic PFC. A, Labeling of PV interneurons in the PFC of a PV-Cre mouse paired with Aig tdTomato reporter mouse, pseudo-colored blue. Left, Coronal section. Right, PV interneurons in different layers of infralimbic PFC, with DAPI labeling in gray. $\boldsymbol{B}$, Similar to $\boldsymbol{A}$ for SOM interneurons in the PFC of a SOM-Cre mouse paired with Ai9 tdTomato reporter mouse, pseudo-colored orange. C, Two-photon images of PV and SOM interneurons. D, AP firing and hyperpolarization in response to $200 \mathrm{pA}$ and $-50 \mathrm{pA}$ current injections in the presence of synaptic blockers. $E$, Summary of resting membrane potential, input resistance, adaptation ratio, and voltage sag. ${ }^{*} p<0.05$.

rons (CS/CA amplitude ratio: PV IPSC $=0.32 \pm 0.08, n=7$ pairs, $p=0.02$; SOM IPSC $=0.36 \pm 0.07, n=8$ pairs, $p=0.01$ ) (Fig. $5 E, G$ ). For both CA and CS neurons, IPSCs generated by PV interneurons also had notably faster kinetics (IPSC decay: PV IPSC $=19.2 \pm 2.7 \mathrm{~ms}, n=14 ;$ SOM IPSC $=32.1 \pm 5 \mathrm{~ms}, n=16$; $p=0.02)$. To eliminate any confounds from presynaptic interneurons firing multiple APs, we also repeated these experiments in the presence of TTX $(1 \mu \mathrm{M}), 4-\mathrm{AP}(100 \mu \mathrm{M})$, and $4 \mathrm{mM}$ extracellular $\mathrm{Ca}^{2+}$. Under these conditions, we again found that PV and SOM interneurons evoked much larger IPSCs at CA neurons (CS/CA amplitude ratio: PV IPSC $=0.44 \pm 0.13, n=7$ pairs, $p=0.02$; SOM IPSC $=0.4 \pm 0.07, n=7$ pairs, $p=0.02$ ) (Fig. $5 E, G$ ). Together, these findings indicate that inhibition from $\mathrm{PV}$ and SOM interneurons is much stronger onto CA neurons.

\section{Strong BLA connections onto PV interneurons}

To drive feedforward inhibition, BLA inputs must also make direct connections onto local interneurons. Inputs to PV interneurons have been shown anatomically (Gabbott et al., 2006) and with in vivo electrophysiology (Dilgen et al., 2013). However, the properties of these connections and the engagement of other interneurons have not been established. Our next goal was to determine whether BLA synapses onto PV and SOM interneurons, and to assess how their activation compares with nearby projection neurons.

To show direct connections onto interneurons, we first used a conditional rabies virus approach (Wickersham et al., 2007a, b) (see Materials and Methods). To perform cell-type-specific, monosynaptic retrograde tracing, we injected AAV-FLEX-RG, AAV-FLEX-TVA-mCherry, and SAD $\Delta$ G-GFP(EnvA) into the PFC of PV-Cre mice (Fig. 6A). After a week, we found GFPexpressing cells in the BLA, which had spiny dendrites consistent with glutamatergic neurons $(n=4$ mice) (Fig. $6 B$ ). These data indicate that BLA projection neurons form monosynaptic connections onto PV interneurons in the PFC but do not reveal the functional properties of these connections.

We next used cell-type-specific recordings and optogenetics to determine the properties of BLA synapses onto PV interneurons. We performed injections of AAV-ChR2-eYFP and retrobeads in the BLA, and AAV-FLEX-tdTomato in the PFC of $P V$-Cre mice (Fig. 6C). We stimulated release by activating ChR2 in BLA terminals and recorded EPSCs from neighboring CA neurons and $\mathrm{PV}$ interneurons. To study monosynaptic connections, we included TTX $(1 \mu \mathrm{M}), 4$-AP $(100 \mu \mathrm{M})$, and elevated extracel- 
A

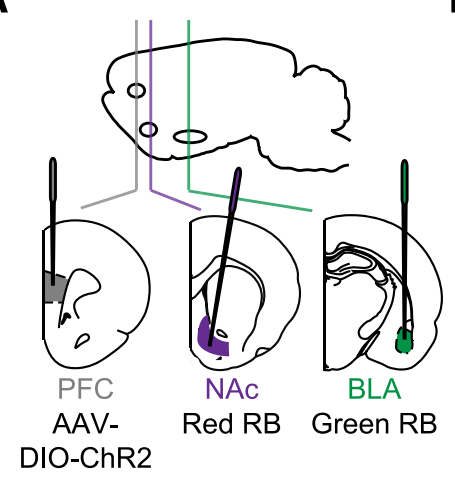

B

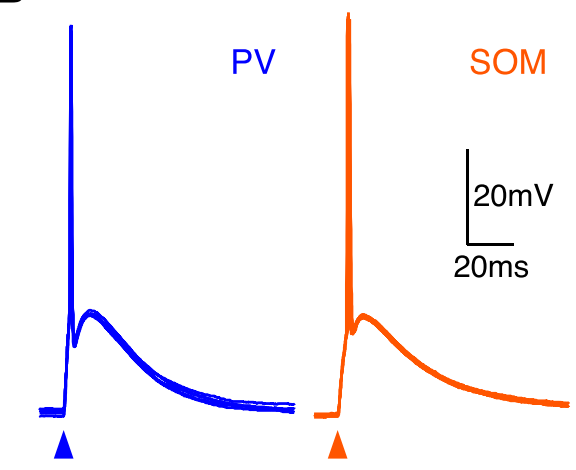

C

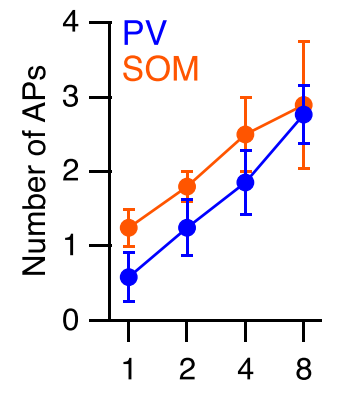

LED duration (ms)
D

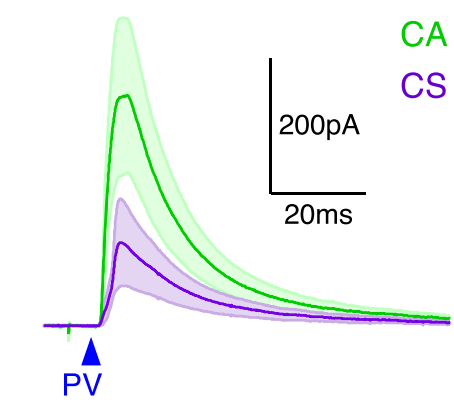

F

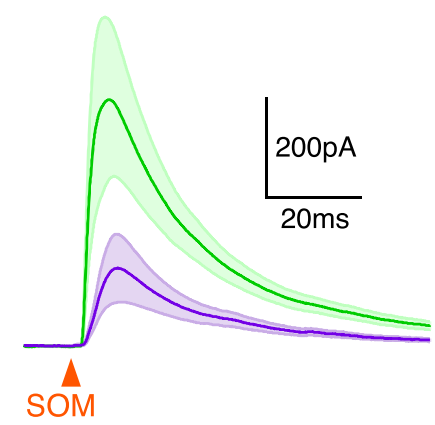

E
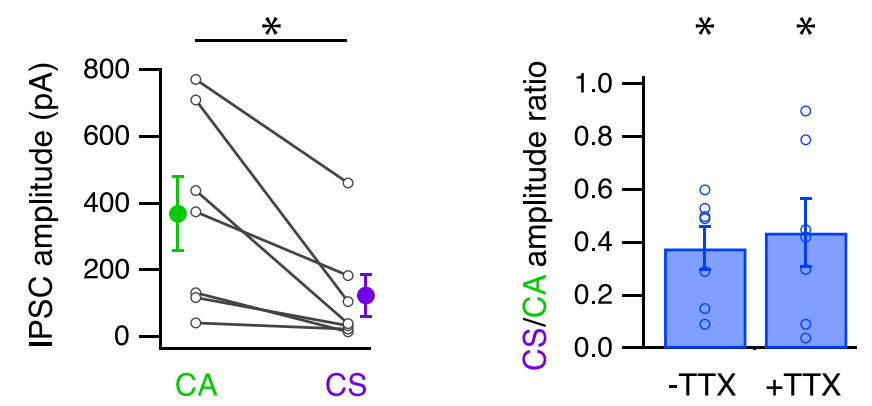

G

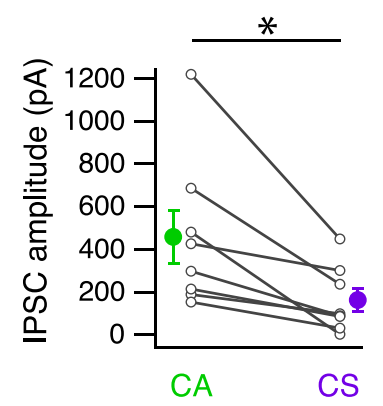

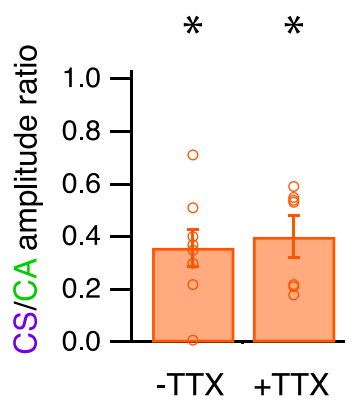

Figure 5. PV and SOM inhibition is stronger at CA neurons. $A$, Schematic of injecting AAV-DIO-ChR2-eYFP into the infralimbic PFC, red retrobeads into the NAC, and green retrobeads into the BLA of either PV-Cre or SOM-Cre mice, to express ChR2 in either PV or SOM interneurons and label CS and CA neurons in the PFC. B, Light-evoked AP firing in PV (blue) and SOM (orange) interneurons expressing ChR2 in the presence of NBQX and CPP, showing multiple trials at a $1 \mathrm{~ms}$ LED duration. Arrowheads indicate time of LED pulse. C, Summary of AP firing over range of LED durations for PV and SOM interneurons. $D$, Average GABA - -R IPSCS evoked by PV interneurons (blue arrowhead) in the presence of NBQX and CPP. E, Summary of amplitudes of PV-evoked IPSCS at CA and CS neurons

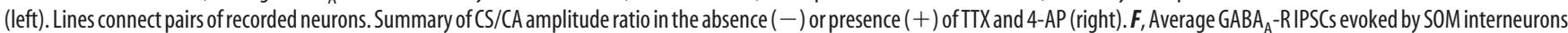
(orange arrowhead) in the presence of NBQX and CPP. G, Summary of amplitudes of SOM-evoked IPSCS at CA and CS neurons (left). Lines connect pairs of recorded neurons. Summary of CS/CA amplitude ratio in the absence $(-)$ or presence $(+)$ of TTX and 4-AP (right). ${ }^{*} p<0.05$.

lular $\mathrm{Ca}^{2+}(4 \mathrm{mM})$. We found that BLA inputs generated large AMPA-R EPSCs and small NMDA-R EPSCs in PV interneurons (Fig. 6D). BLA-evoked AMPA-R EPSCs were notably larger onto PV interneurons than neighboring CA neurons (PV/CA amplitude ratio $=3.9 \pm 1.1, n=9$ pairs, $p=0.008)$, whereas the NMDA-R EPSCs were smaller (PV/CA amplitude ratio $=0.64 \pm$ $0.13, n=9$ pairs, $p=0.02$ ) (Fig. $6 E$ ). A small NMDA-R component at PV interneurons is consistent with the finding that fastspiking interneurons in the PFC have little NMDA-R currents (Wang and Gao, 2009). Consequently, PV interneurons had a much higher AMPA/NMDA ratio than CA neurons $(\mathrm{CA}=2.6 \pm$ $0.6, \mathrm{PV}=19.2 \pm 7.3, n=9$ pairs, $p=0.008$ ) (Fig. $6 F$ ). These results indicate that the BLA makes stronger connections onto PV interneurons compared with CA neurons.

Excitatory inputs can also have unique presynaptic properties onto different classes of interneurons (Reyes et al., 1998; Beierlein et al., 2003). We next tested for differences in presynaptic release by examining responses to trains of BLA stimulation. In the absence of TTX and 4-AP, we found that trains of BLA inputs elicited AMPA-R EPSCs at these two cell types (Fig. 6G). All EPSCs were larger at PV interneurons, with a constant PV/CA amplitude ratio during the trains ( $n=7$ pairs) (Fig. $6 H$ ). BLA synapses were also markedly depressing at both cell types, with similar PPR across pulses ( $n=7$ pairs) (Fig. $6 H$ ). Together, these findings indicate that BLA inputs have different postsynaptic strengths but similar presynaptic properties at CA neurons and PV interneurons.

\section{Facilitating BLA connections onto SOM interneurons}

We next used a similar combination of approaches to examine the BLA inputs onto SOM interneurons in the PFC. We first explored anatomical connection using the conditional rabies vi- 
A

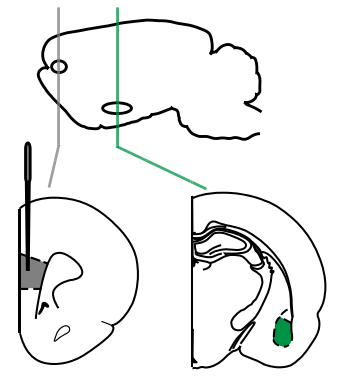

PFC

AAV-FLEX-RG

AAV-FLEX-TVA-mCherry

$\mathrm{SAD} \Delta \mathrm{G}-\mathrm{GFP}(\mathrm{EnvA})$
B

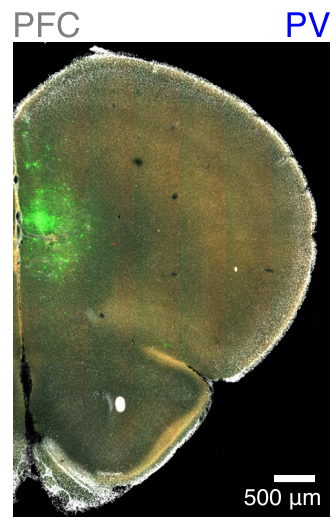

BLA

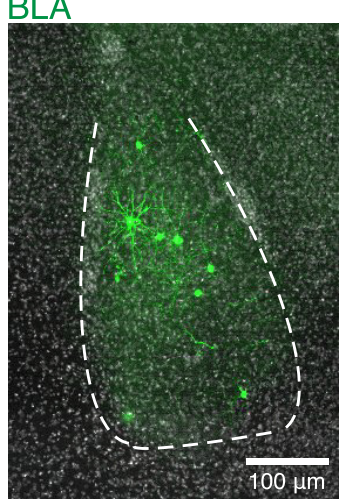

C

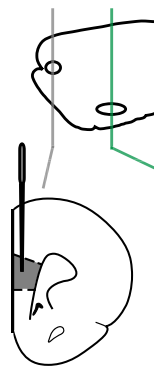

PFC

AAV-FLEX -tdTomato

E

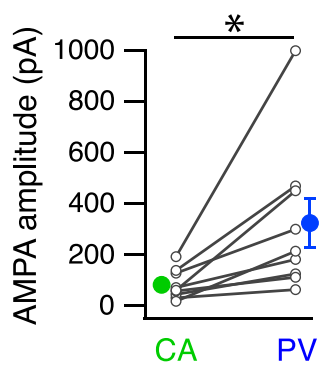

D

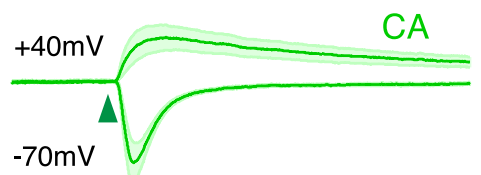

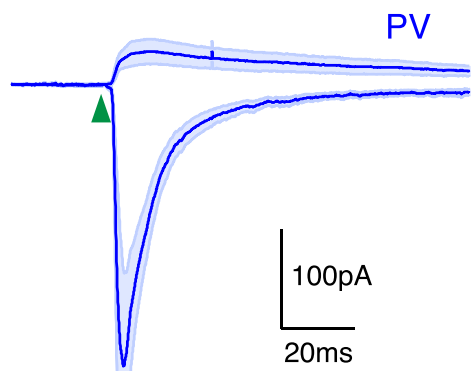

$\mathbf{F}$

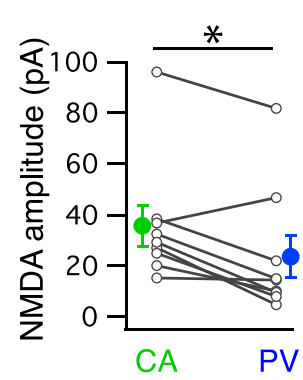

H
G

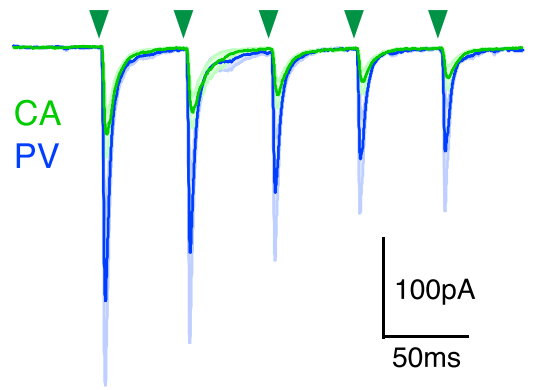

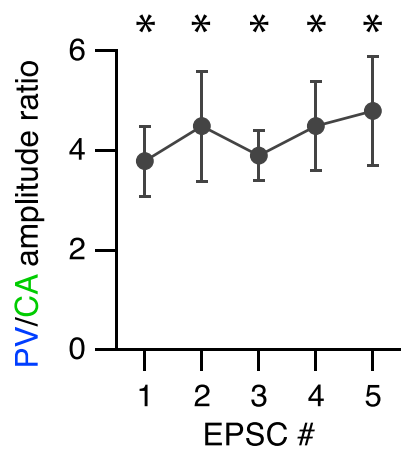

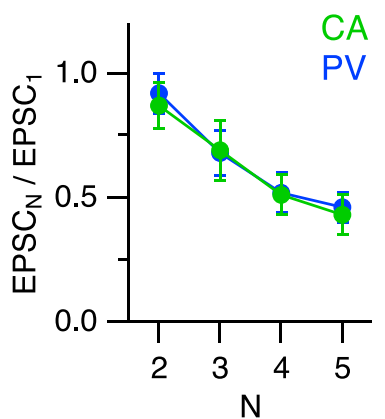

Figure 6. BLA inputs are strongest at PV interneurons. $A$, Schematic of injecting AAV-FLEX-RG, AAV-FLEX-TVA-mCherry, and SAD $\triangle G$ GFP(EnvA) into the PFC of $P V-C r e$ mice, to retrogradely label monosynaptically connected cells in the BLA. $B$, Left, Coronal image showing the injection site in the PFC. Right, GFP-expressing neurons in the BLA that project to PV interneurons. C, Schematic of injecting AAV-FLEX-tdTomato into the PFC and green beads and AAV-ChR2-eYFP into the BLA of PV-Cre mice, to label PV interneurons and CA neurons and express ChR2 in BLA axons in the infralimbic PFC. D, Average BLA-evoked AMPA-R and NMDA-R EPSCs in the presence of TTX, 4-AP, high $\mathrm{Ca}^{2+}$, and gabazine. Green arrowhead indicates time of LED pulse. $E$, Summary of amplitudes of BLA-evoked AMPA (left) and NMDA (middle) EPSCs at CA and PV neurons. Lines connect pairs of recorded neurons. Summary of PV/CA amplitude ratio (right). $\boldsymbol{F}$, Summary of AMPA/NMDA ratio at CA and PV neurons. G, Average AMPA-R EPSCs evoked by trains of BLA inputs (5 pulses at $20 \mathrm{~Hz})$ in the presence of CPP and gabazine. Green arrowheads indicate timing of LED pulses. $\boldsymbol{H}$, Summary of PV/CA amplitude ratio (left) and PPR (right) during trains. ${ }^{*} p<0.05$. 
A

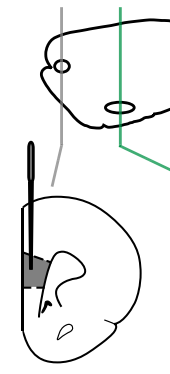

PFC
AAV-FLEX-RG

AAV-FLEX-TVA-mCherry SAD $\triangle$ G-GFP(EnvA)
B

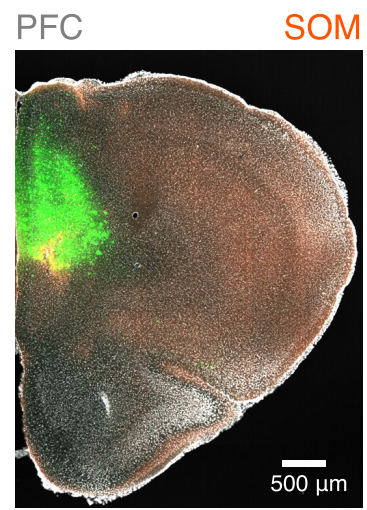

BLA

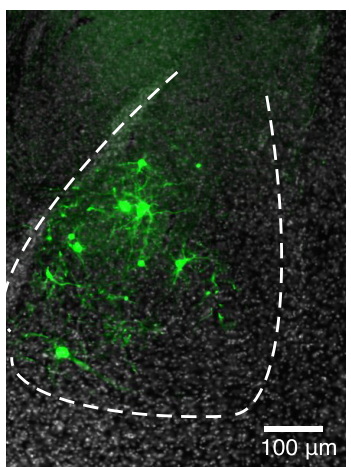

C

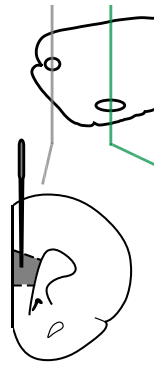

PFC
AAV-FLEX -tdTomato

E

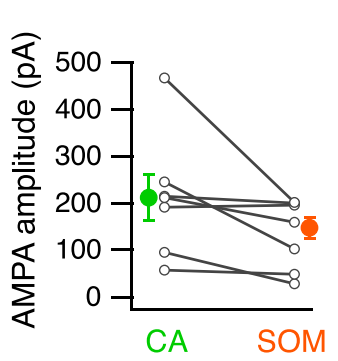

BLA

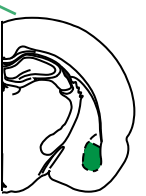

D

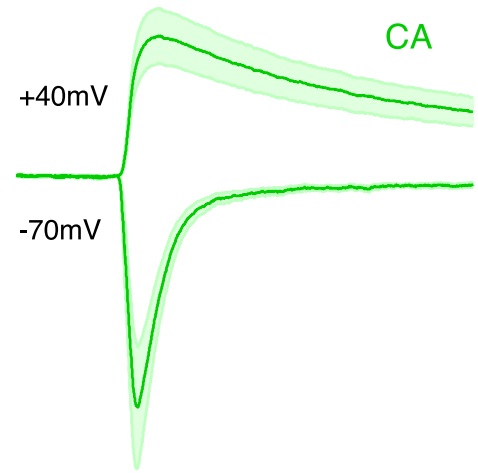

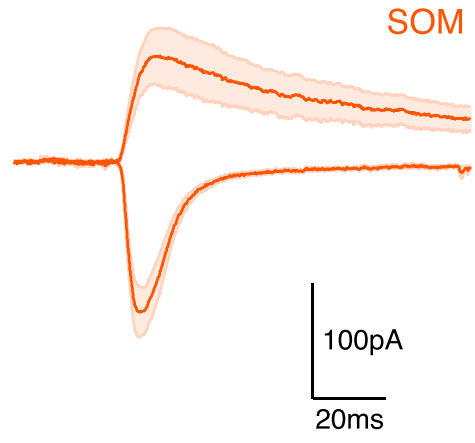

$\mathbf{F}$

G
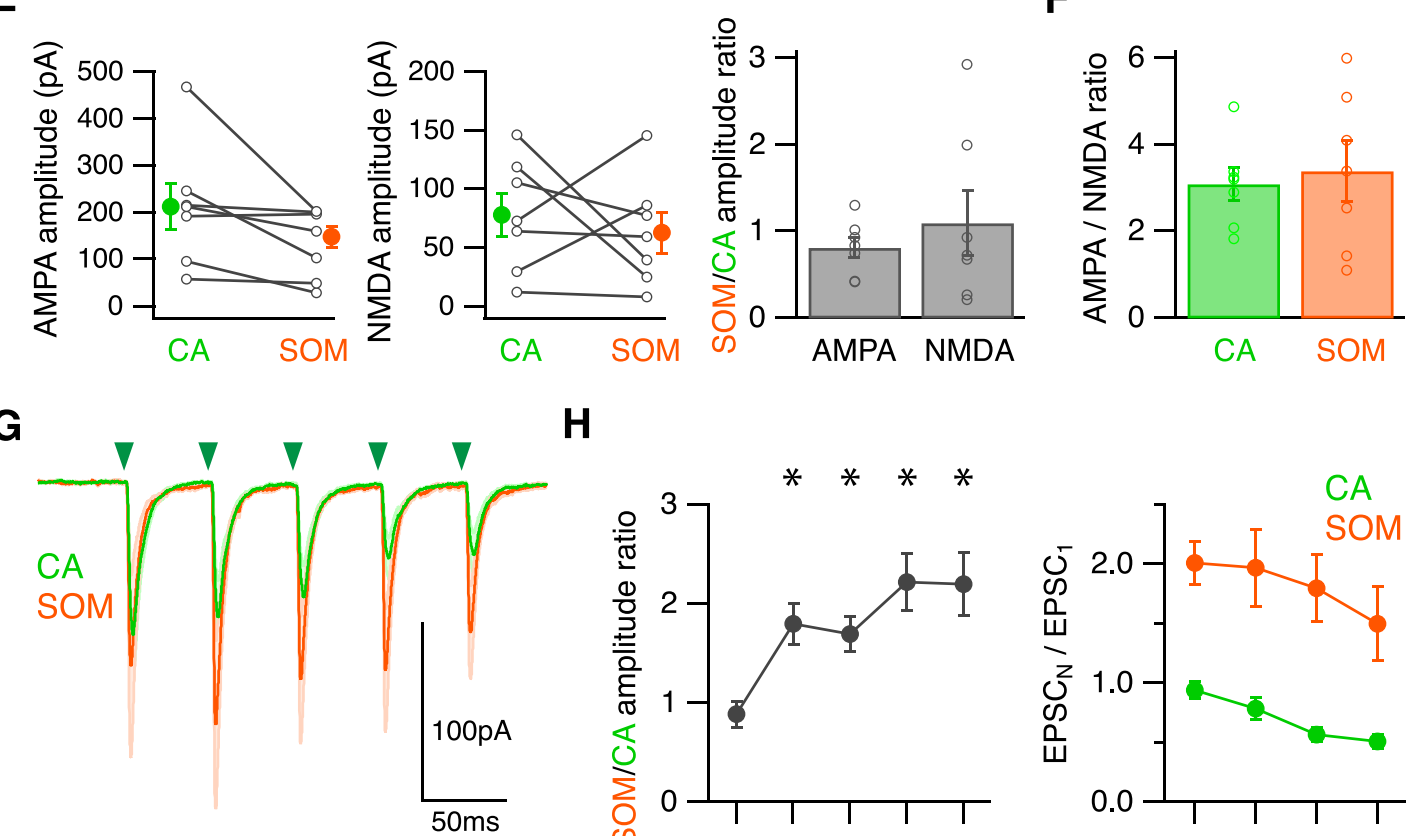

H
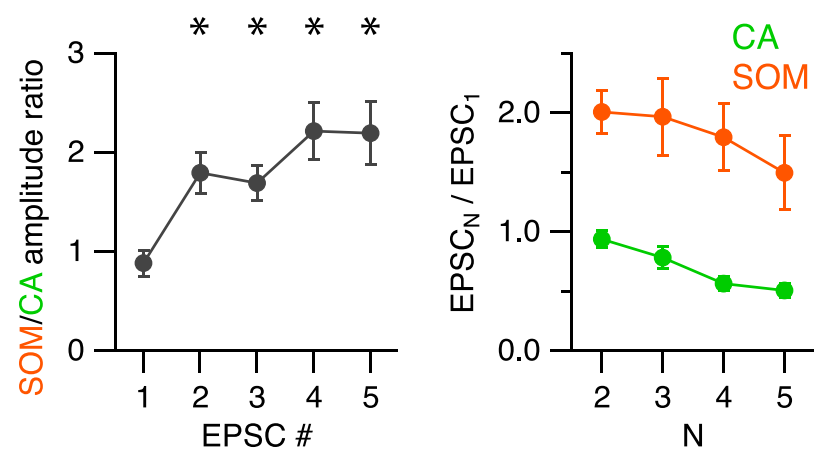

Figure 7. Facilitating BLA inputs onto SOM interneurons. $A$, Schematic of injecting AAV-FLEX-RG, AAV-FLEX-TVA-mCherry, and SAD $\triangle G$-GFP(EnvA) into the PFC of SOM-Cre mice, to retrogradely label monosynaptically connected cells in the BLA. $B$, Left, Coronal image showing the injection site in the PFC. Right, GFP-expressing neurons in the BLA that project to SOM interneurons. C, Schematic of injecting AAV-FLEX-tdTomato into the PFC and green beads and AAV-ChR2-eYFP into the BLA of SOM-Cre mice, to label SOM interneurons and CA neurons and express ChR2 in BLA axons in the infralimbic PFC. D, Average BLA-evoked AMPA-R and NMDA-R EPSCs in the presence of TTX, 4-AP, high Ca ${ }^{2+}$, and gabazine. Green arrowhead indicates time of LED pulse. $E$, Summary of amplitudes of BLA-evoked AMPA (left) and NMDA (middle) EPSCS at CA and SOM neurons. Lines connect pairs of recorded neurons. Right, Summary of SOM/CA amplitude ratio. $\boldsymbol{F}$, Summary of AMPA/NMDA ratio at CA and SOM neurons. $G$, Average AMPA-R EPSCs evoked by trains of BLA inputs (5 pulses at $20 \mathrm{~Hz}$ ) in the presence of CPP and gabazine. Green arrowheads indicate timing of LED pulses. $\boldsymbol{H}$, Summary of SOM/CA amplitude ratio (left) and PPR (right) during trains. ${ }^{*} p<0.05$. 
rus strategy in SOM-Cre mice (Fig. 7A). We observed monosynaptic inputs onto SOM interneurons from neurons within the BLA ( $n=5$ mice) (Fig. $7 B)$. We then measured synaptic responses at pairs of CA neurons and SOM interneurons, performing injections of AAV-ChR2-eYFP and retrobeads in the BLA, and AAV-FLEX-tdTomato in the PFC of SOM-Cre mice (Fig. $7 C)$. We found that BLA inputs also evoked robust AMPA-R and NMDA-R EPSCs at SOM interneurons (Fig. 7D). Both AMPA-R and NMDA-R EPSCs were similar at SOM interneurons and CA neurons (SOM/CA amplitude ratio: AMPA-R EPSC $=0.81 \pm$ $0.12, p=0.13$; NMDA-R EPSC $=1.11 \pm 0.38, p=0.4 ; n=7$ pairs) (Fig. $7 E$ ). Consequently, AMPA/NMDA ratios were also equivalent at these two cell types $(\mathrm{CA}=3.1 \pm 0.4, \mathrm{SOM}=3.4 \pm$ $0.7, n=7$ pairs, $p=0.4$ ) (Fig. $7 F$ ). A substantial NMDA-R component in SOM interneurons is consistent with the finding that low threshold spiking interneurons in the PFC maintain NMDA-R currents (Wang and Gao, 2009). These results indicate that the BLA also makes robust connections onto SOM interneurons, in addition to their inputs onto PV interneurons.

To assess presynaptic properties, we found that trains of BLA inputs also elicit robust AMPA-R EPSCs at these two cell types (Fig. 7G). However, these EPSCs progressively diverged with subsequent pulses, leading to an increase in the SOM/CA amplitude ratio $(n=8$ pairs) (Fig. $7 H)$. This results from a combination of depression at CA neurons and marked facilitation at SOM interneurons during trains $(n=8$ pairs) (Fig. $7 H)$. Together, these findings indicate that BLA connections have unique postsynaptic and presynaptic properties at distinct classes of interneurons and projection neurons, which could allow for the differential activation of these four distinct cell types within the PFC circuit.

\section{Impact of targeted BLA inputs on neuronal firing}

Our findings reveal unique properties of BLA connections onto four populations of neurons in the PFC. AMPA-R EPSCs are largest at $\mathrm{PV}$ interneurons, equivalent at SOM interneurons and CA neurons, and weakest at CS neurons. Ultimately, the activation of these neurons reflects a combination of synaptic conductances and intrinsic properties. To assess the order of activation, we first injected the average AMPA-R EPSCs recorded at each of these cell types. We scaled all EPSCs relative to CA neurons, based on the ratios that we measured in our experiments (Fig. $8 A$ ). To mimic a range of stimulus strengths, we further multiplied these EPSCs by a scale factor (Fig. $8 B$ ). Over a wide range of scales, these EPSCs elicited suprathreshold EPSPs that evoked APs at CA $(n=$ $7)$, PV $(n=7)$, and SOM $(n=8)$ neurons, but only subthreshold EPSPs at CS $(n=7)$ neurons (Fig. $8 C)$. Interestingly, we found that PV neurons first fired APs, followed by SOM interneurons, and finally CA neurons (Fig. 8D). Moreover, PV interneurons often fired multiple APs, even before CA neurons could fire a single AP (Fig. 8D). These results suggest that both PV and SOM interneurons are activated by BLA inputs, allowing them to contribute to feedforward inhibition in the PFC.

To validate these predictions, we next performed currentclamp experiments with optogenetic stimulation of BLA inputs. We injected AAV-ChR2-eYFP and retrobeads in the BLA, and AAV-FLEX-tdTomato in the PFC of PV-Cre or SOM-Cre mice. We recorded in the absence of TTX and 4-AP, but in the presence of gabazine to block inhibition. As local recurrent activity was intact, we adjusted the LED intensity to evoke EPSPs and APs at short latencies. Under conditions that evoked robust AP firing of PV interneurons, we found only subthreshold EPSPs at CA neurons (Fig. $8 E$ ). The probability of PV interneuron firing increased with greater stimulation of BLA inputs ( $n=7$ pairs) (Fig. $8 E$ ).
Similarly, we observed pronounced AP firing of SOM interneurons during subthreshold EPSPs at CA neurons (Fig. $8 F$ ). The probability of firing an AP in the SOM interneuron also increased with greater BLA stimulation ( $n=7$ pairs) (Fig. $8 F$ ). Together, these findings indicate that BLA inputs are capable of triggering feedforward inhibition by activating both PV and SOM interneurons before CA neurons in the PFC.

\section{Synaptic dynamics create two time periods of inhibition}

Our findings show that BLA synapses exhibit marked depression at CA, CS, and PV neurons, but robust facilitation at SOM interneurons. To study the impact of these short-term dynamics, we next assessed responses to injection of experimentally recorded AMPA-R EPSC trains, scaled to CA as described above for single EPSCs (Fig. 9A,B). At low-scale factors, AP firing only occurred at PV and SOM interneurons, with PV interneurons $(n=7)$ firing at the beginning of the train, and SOM interneurons $(n=8)$ in the middle (Fig. $9 C, D)$. At high-scale factors, SOM interneurons fired throughout the train, whereas probability of PV firing successively declined (Fig. 9D). At the highest scale factors, CA neurons $(n=7)$ could also fire APs, but only at the beginning of the train (Fig. 9D). However, CS neurons $(n=7)$ never fired APs for any of the scale factors that we tested. These findings suggest that PV interneurons fire APs near the onset of repetitive BLA activity, whereas SOM interneurons are progressively recruited over time.

To test these predictions, we performed current-clamp experiments with optogenetic stimulation of BLA inputs. We injected AAV-ChR2-eYFP and retrobeads in the BLA, and AAV-FLEXtdTomato in the PFC of $P V$-Cre or SOM-Cre mice. We measured responses to BLA input at pairs of neighboring neurons in current-clamp recordings. We found that $20 \mathrm{~Hz}$ stimulation elicited depressing EPSPs at CA neurons and PV interneurons, with firing at the start of the train for PV interneurons ( $n=7$ pairs) (Fig. 9E). In contrast, we found that $20 \mathrm{~Hz}$ stimulation elicited facilitating EPSPs and AP firing at SOM interneurons $(n=7$ pairs) (Fig. $9 F$ ). Together, these findings indicate that the depression of BLA inputs onto PV interneurons and facilitation onto SOM interneurons creates two temporally distinct windows during which these interneurons contribute to inhibition.

\section{Discussion}

We have established how the BLA engages different populations of $\mathrm{L} 2$ projection neurons and interneurons in the infralimbic PFC. We found that BLA inputs preferentially target CA neurons that send reciprocal connections to the BLA. However, these inputs are even more effective at firing PV and SOM interneurons, leading to feedforward inhibition. Interestingly, interneuron inputs are also biased onto CA neurons compared with neighboring CS neurons. Finally, synaptic dynamics differ at these connections, with facilitating trains at SOM interneurons leading to broader inhibition. Together, these findings reveal a mechanism for how BLA activity can drive robust inhibition in the PFC.

\section{BLA inputs preferentially target CA neurons}

The PFC projects to a variety of other brain regions (Gabbott et al., 2005) to exert top-down control of behavior (Groenewegen and Uylings, 2000; Euston et al., 2012). We focused on two intermingled but distinct projection neurons in the infralimbic PFC that project to either the BLA or NAc. We found CA and CS neurons have indistinguishable dendritic morphology and intrinsic physiology. Although BLA inputs overlap with the dendrites of both CA and CS neurons, excitatory synaptic responses 
A

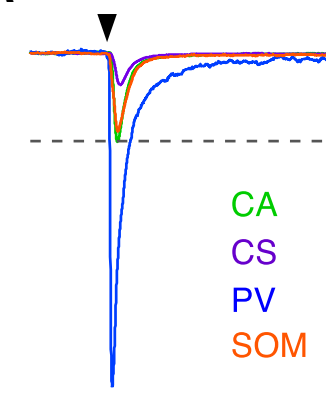

C

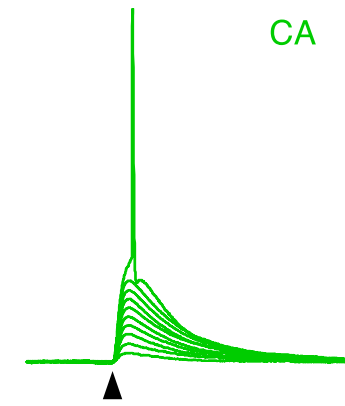

B
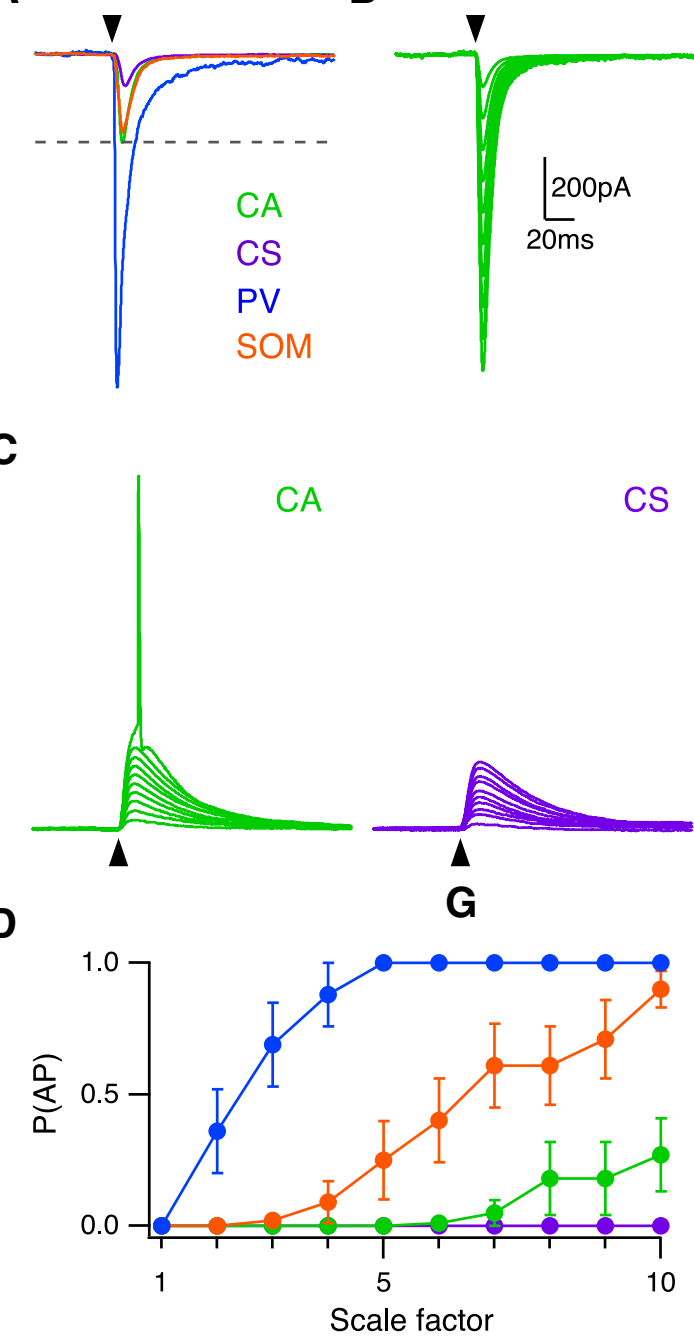

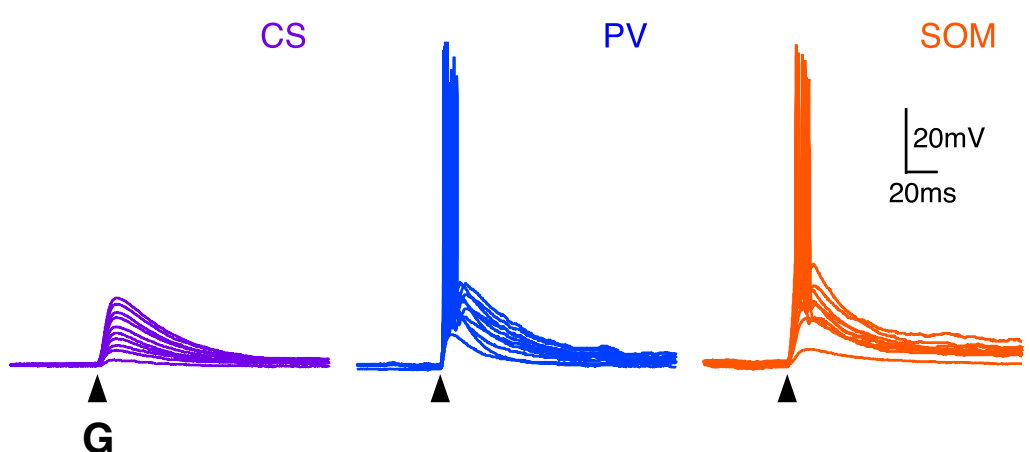

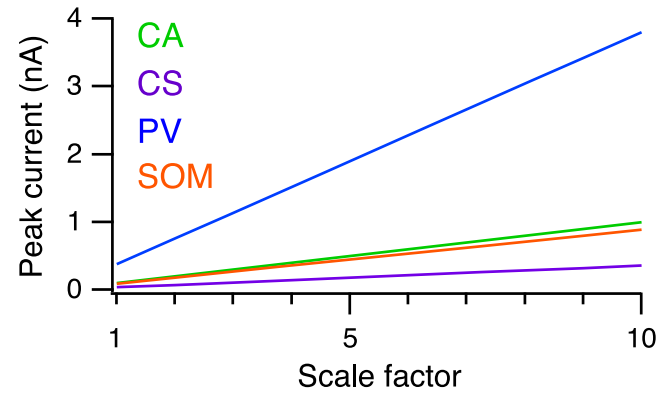

Scale factor

E

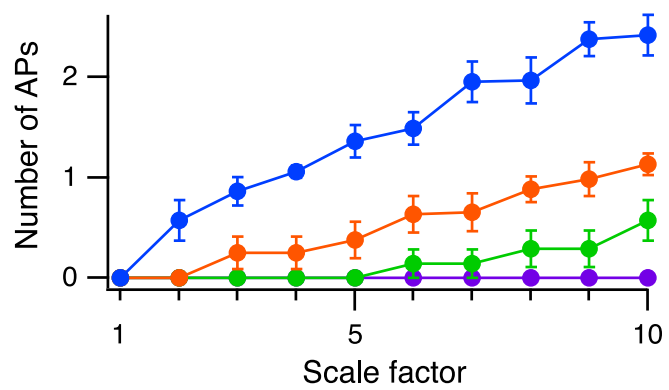

$\mathbf{F}$
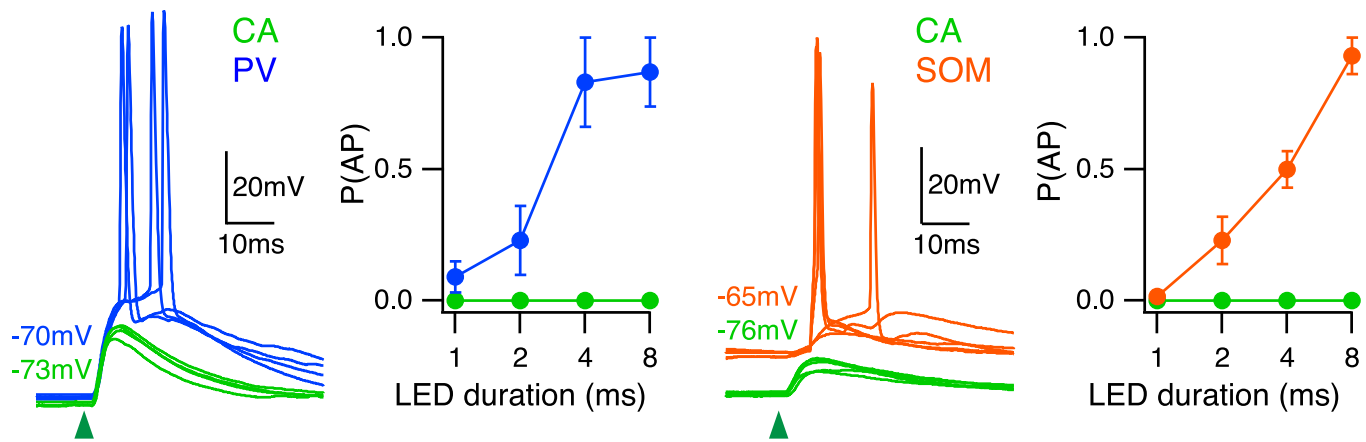

LED duration (ms)

Figure 8. BLA inputs preferentially activate interneurons. $A$, Average experimentally recorded BLA-evoked EPSCs scaled relative to CA neuron response. Black arrowhead indicates time of current injection. $B$, Left, CA neuron EPSCs over scale factors 1-10 used for current injections. Black arrowhead indicates time of current injection. Right, Peak current of injected EPSC over scale factors 1-10 for each cell type. C, EPSPs and APs elicited by EPSC current injections over scale factors 1-10 in CA (green), CS (purple), PV (blue), and SOM (orange) neurons, in the presence of synaptic blockers. Black arrowhead indicates time of current injection. $\boldsymbol{D}$, Summary of probability of AP firing (left) and number of evoked APs (right) as a function of scale factor. E, Left, BLA-evoked EPSPs and APs at neighboring CA neurons (green) and PV interneurons (blue), in the presence of (PP and gabazine. Responses to LED duration of $4 \mathrm{~ms}$ shown. Green arrowhead indicates time of LED pulse. Right, Probability of AP firing versus LED duration. $\boldsymbol{F}$, Same as in $\boldsymbol{E}$ for CA neurons (green) and SOM interneurons (orange).

were significantly larger at CA neurons. The differences in responses were similar for AMPA-R and NMDA-R EPSCs, resulting in identical AMPA/NMDA ratios at CA and CS neurons. PPR was also similar during trains of synaptic activity, indicating equivalent presynaptic properties at these neurons (Zucker and Regehr, 2002). These results are consistent with the idea of more numerous synaptic connections made by BLA inputs onto CA neurons in the prelimbic PFC (Little and Carter, 2013). Our findings suggest that BLA inputs may activate CA neurons to drive reciprocal interactions, but may be less effective at activating CS neurons to drive top-down control of striatal circuits in the NAc. 
A

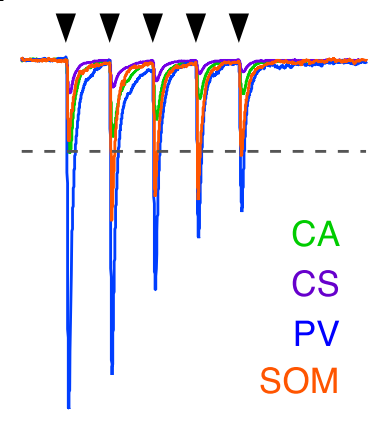

C

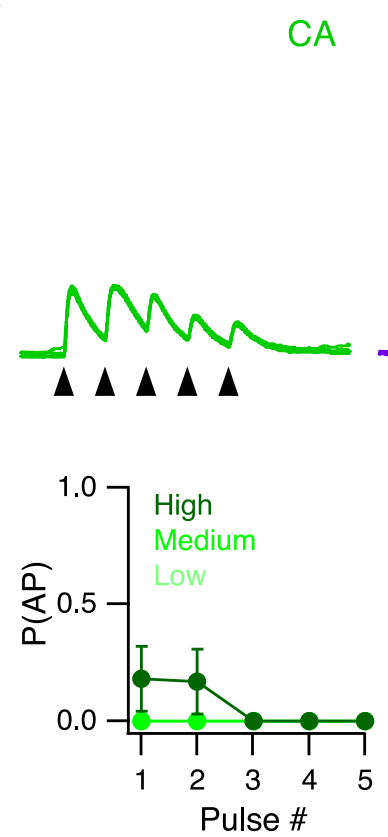

B

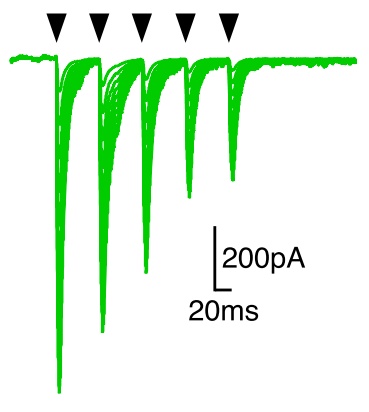

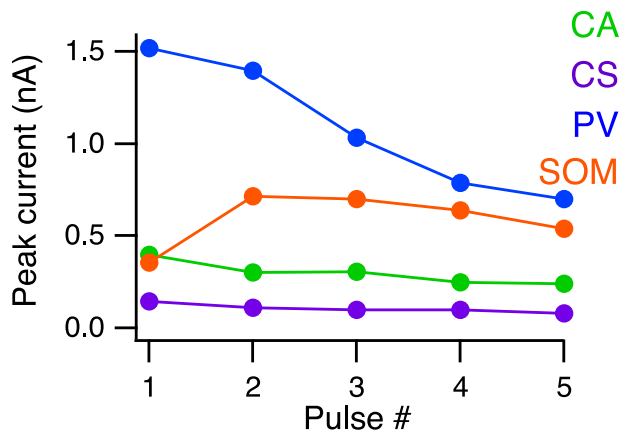

CA

CS

PV
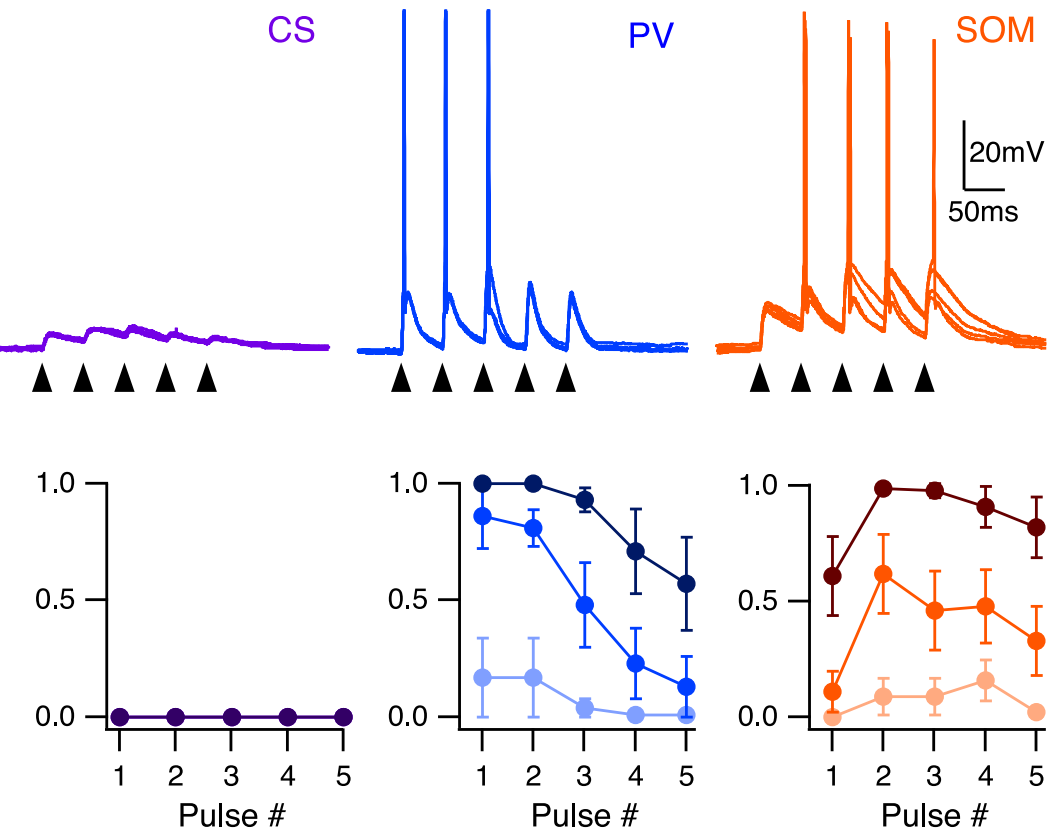

E

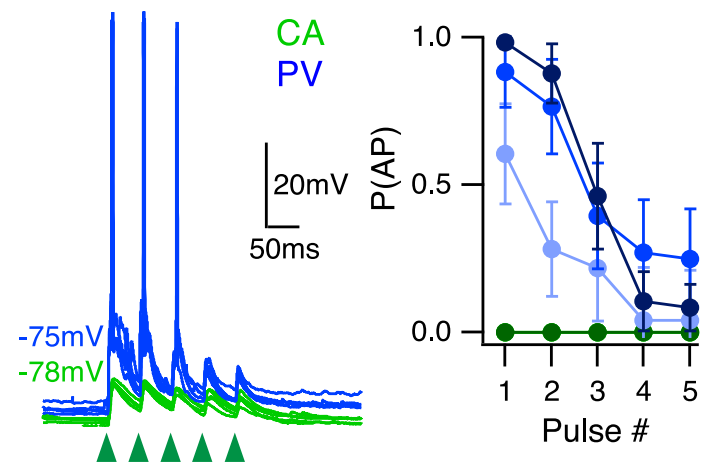

F
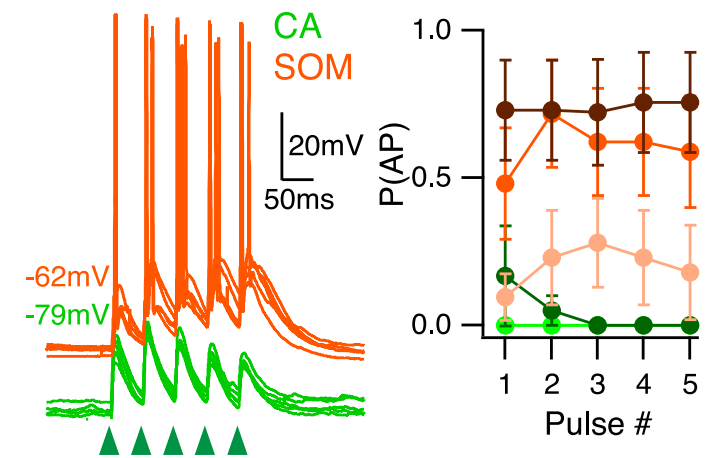

Figure 9. Unique activation during trains of BLA inputs. A, Average experimentally recorded BLA-evoked EPSC trains scaled relative to CA neuron response. Black arrowheads indicate timing of current injections. B, Left, CA neuron EPSC trains over scale factors 1-10 used for current injections. Black arrowheads indicate timing of current injections. Right, Peak current of injected EPSCs within a train at scale factor of 4 for each cell type. C, EPSPs and APs elicited by EPSC train current injections (5 pulses at $20 \mathrm{~Hz}$ ) in CA (green), CS (purple), PV (blue), and SOM (orange) neurons, in the presence of synaptic blockers. Responses to scale factor of 4 shown. Black arrowheads indicate timing of current injections. D, Summary of probability of AP firing as a function of pulse number, with low (2), medium (4), and high (8) scale factors shown in light to dark shades. $E$, Left, EPSPs and APs evoked at neighboring CA neurons (green) and PV interneurons (blue) in response to train of BLA inputs ( 5 pulses at $20 \mathrm{~Hz}$ ), in the presence of (PP and gabazine. Responses to LED duration of $4 \mathrm{~ms}$ shown. Green arrowheads indicate timing of LED pulses. Right, Probability of AP firing versus pulse number, with LED durations of 2, 4, and $8 \mathrm{~ms}$ shown in light to dark shades. $\boldsymbol{F}$, Same as in $\boldsymbol{E}$ for CA neurons (green) and SOM interneurons (orange).

Inhibitory inputs selectively contact CA neurons

Although BLA inputs are excitatory, stimulation of the BLA strongly suppresses pyramidal cell firing in vivo (Floresco and Tse, 2007; Dilgen et al., 2013). In agreement with these observa- tions, we found that BLA inputs generate robust feedforward inhibition of both CA and CS neurons. Interestingly, these IPSCs were also stronger onto CA neurons, resulting in similar EPSC/ IPSC ratios at CA and CS neurons. This finding suggested that 
inhibitory responses to local interneuron inputs were also stronger at CA neurons.

Using optogenetics, we established that both PV and SOM interneurons make stronger connections onto CA than CS neurons. Previous studies have shown specific connections from PV interneurons onto distinct populations of projection neurons (Lee et al., 2014; Rock and Apicella, 2015). In other cortical areas, the connections from PV and SOM interneurons onto pyramidal neurons are dense (Fino and Yuste, 2011; Packer and Yuste, 2011), and connection probability can often be explained primarily by the spatial overlap of interneuron axons and pyramidal cell dendrites (Levy and Reyes, 2012; Packer et al., 2013). Our results highlight that the strength of inhibition from both PV and SOM interneurons also critically depends on the type of postsynaptic neuron.

Excitation/Inhibition (E/I) balance in the PFC is important for information transfer and is reflected in high-level behaviors (Yizhar et al., 2011). Despite their different excitatory and inhibitory inputs, we observed that the E/I balance is remarkably similar at CA and CS neurons. One possibility is that homeostatic mechanisms adjust the strength or number of synapses onto these cells (Turrigiano, 2011). Although E/I balancing often involves PV interneurons in other brain regions (Xue et al., 2014), our findings suggest fine-tuning of connections from SOM interneurons could also contribute in the PFC.

\section{BLA inputs are strongest onto interneurons}

To drive feedforward inhibition, BLA inputs must activate GABAergic interneurons in the PFC. Using a conditional rabies approach, we found monosynaptic connections from the BLA onto PV and SOM interneurons. Using optogenetics, we found that BLA inputs also generated robust EPSCs in both classes of interneurons. PV interneurons had larger AMPA-R EPSCs and higher AMPA/NMDA ratios compared with CA neurons, as observed for thalamic inputs in other cortices (Beierlein et al., 2003; Cruikshank et al., 2007, 2010; Hull et al., 2009). In contrast, SOM interneurons had similar AMPA-R and NMDA-R EPSCs compared with CA neurons, leading to equivalent AMPA/NMDA ratios. Our results indicate that BLA inputs contact both PV and SOM interneurons, but with markedly different postsynaptic properties.

The order in which these different cell types are activated depends on both their synaptic conductances and intrinsic properties. Despite similar intrinsic physiological properties, CA neurons fire before CS neurons, due to their stronger BLA inputs. However, SOM interneurons fire before CA neurons, due to equivalent BLA inputs, but greater excitability of SOM interneurons. Finally, PV interneurons fire before SOM interneurons and CA neurons, due to their stronger BLA inputs compared with all other cell types. These findings demonstrate that both classes of interneurons are readily activated before projection neurons. Thus, the BLA ultimately has a robust inhibitory influence on the PFC via feedforward inhibition mediated by both PV and SOM interneurons.

Both PV and SOM interneurons consist of several subtypes, with diversity in physiology, morphology, and additional molecular markers (Markram et al., 2004). Within PV interneurons, two main subtypes are basket cells and chandelier cells, distinguished by their morphology, physiology, and distinct anatomical targeting of projection neurons (Kawaguchi and Kubota, 1997, 1998; Woodruff et al., 2009). SOM interneurons are primarily Martinotti cells (Kawaguchi and Kubota, 1997, 1998; Wang et al., 2004), but other subtypes have been described with differences in axonal morphology and physiology (Ma et al., 2006; McGarry et al., 2010). In future studies, it will be particularly interesting to further examine whether additional subpopulations of PV and SOM interneurons receive distinct BLA inputs and selectively inhibit CA neurons in the PFC.

\section{Synaptic dynamics during trains}

The strength of synapses evolves during repetitive activity, reflecting changes in presynaptic release (Zucker and Regehr, 2002). We found that BLA inputs were strongly depressing at CA neurons, CS neurons, and PV interneurons, but facilitating at SOM interneurons. One explanation is that the presynaptic properties of BLA inputs differ depending on the postsynaptic target, as seen for local connections (Reyes et al., 1998). For example, excitatory inputs onto PV interneurons are often depressing, whereas those onto SOM interneurons can facilitate (Reyes et al., 1998; Beierlein et al., 2003; Tan et al., 2008). Another untested possibility is that a different population of projection neuron in the BLA may selectively contact SOM interneurons in the PFC.

The distinct dynamics of BLA inputs has implications for the functional activation of different cell types. As a consequence of depressing inputs, CA neurons, CS neurons, and PV interneurons are activated at the start of trains. In contrast, strongly facilitating inputs result in enhanced engagement of SOM interneurons over the course of trains. These results suggest two circuits for feedforward inhibition, with rapid PV inhibition followed by sustained SOM inhibition. In the future, it will be important to determine whether the short-term dynamics we observed with optogenetic stimulation in slice are present in vivo. It will also be interesting to assess the consequence of subcellular targeting of these different classes of interneurons. For example, PV interneurons primarily target the soma and axon of pyramidal neurons (Somogyi, 1977), whereas SOM interneurons primarily target the dendrites (Kawaguchi and Kubota, 1997, 1998; Marlin and Carter, 2014). Thus, differential activation timing of these interneurons could shift inhibition along the somatodendritic axis (Pouille and Scanziani, 2004).

\section{Comparison with other cortical circuits}

In many cortical areas, thalamic inputs strongly drive PV interneurons, resulting in feedforward inhibition (Beierlein et al., 2003; Gabernet et al., 2005; Sun et al., 2006; Cruikshank et al., 2007, 2010; Hull et al., 2009). In contrast, SOM interneurons are driven by local pyramidal neurons, leading to feedback inhibition (Kapfer et al., 2007; Silberberg and Markram, 2007). Previous studies indicate that thalamic inputs to the PFC also preferentially engage PV but not SOM interneurons (Delevich et al., 2015). In contrast, we find that BLA inputs strongly activate PV and SOM interneurons in the PFC, and both contribute to feedforward inhibition. Despite these differences, our results are consistent with other findings that non-PV interneurons can in some cases also participate in feedforward inhibition (Stokes and Isaacson, 2010; Cruikshank et al., 2012). Further studies are now needed to explore whether additional long-range excitatory inputs to the PFC can also engage SOM interneurons.

Given the presence of this strong feedforward inhibition, how can BLA inputs activate projection neurons within the PFC? In other parts of cortex, the synchronous activation of thalamic inputs can drive excitatory neurons before interneurons (Bruno and Sakmann, 2006; Bruno, 2011). This creates a "window of opportunity" for excitation, resulting in selective gating of information relayed to cortex, and resulting in sparse and precise coding (Bruno, 2011). Future studies are needed to determine 
whether BLA inputs are also synchronously activated by external or internal stimuli, and thus able to similarly escape feedforward inhibition to drive projection neurons in the PFC.

Another possibility is that disinhibitory networks in the PFC allow BLA inputs to activate projection neurons. PV interneurons are often inhibited by themselves and SOM interneurons (Gibson et al., 1999; Pfeffer et al., 2013), whereas SOM interneurons are inhibited by VIP interneurons (Jiang et al., 2013; Pfeffer et al., 2013). Activation of VIP interneurons in the superficial layers is thought to result in disinhibition of PFC, as seen in other circuits (Letzkus et al., 2011; Lee et al., 2013; Pi et al., 2013; Fu et al., 2014). In the future, it will be interesting to determine whether activation of disinhibitory pathways allows excitatory inputs to activate the PFC despite robust feedforward inhibition.

\section{Functional importance of BLA to PFC communication}

Together, our results provide a mechanism for how BLA inputs generate feedforward inhibition in the PFC. Bidirectional interactions between PFC and BLA play a key role in regulating emotional behaviors (Sotres-Bayon and Quirk, 2010; Felix-Ortiz et al., 2016; Karalis et al., 2016). Connections from the BLA to PFC are thought to add emotional valence for decision-making and cognitive planning (Laviolette et al., 2005; Herry et al., 2008; Sotres-Bayon et al., 2012). Altered interactions between the PFC and BLA contribute to pathological states, including anxiety and stress (Likhtik et al., 2014; FelixOrtiz et al., 2016). Our findings of inhibitory control over BLA to PFC interactions are consistent with recent studies that highlight the influence of different interneurons within the PFC in emotional behavior (Yizhar et al., 2011; Kvitsiani et al., 2013; Courtin et al., 2014; Sparta et al., 2014). In conclusion, the BLA recruits inhibitory circuits that drive robust feedforward inhibition of specific projection neurons in the PFC.

\section{References}

Beierlein M, Gibson JR, Connors BW (2003) Two dynamically distinct inhibitory networks in layer 4 of the neocortex. J Neurophysiol 90:29873000. CrossRef Medline

Bruno RM (2011) Synchrony in sensation. Curr Opin Neurobiol 21: 701-708. CrossRef Medline

Bruno RM, Sakmann B (2006) Cortex is driven by weak but synchronously active thalamocortical synapses. Science 312:1622-1627. CrossRef Medline

Chalifoux JR, Carter AG (2010) GABAB receptors modulate NMDA receptor calcium signals in dendritic spines. Neuron 66:101-113. CrossRef Medline

Courtin J, Chaudun F, Rozeske RR, Karalis N, Gonzalez-Campo C, Wurtz H, Abdi A, Baufreton J, Bienvenu TC, Herry C (2014) Prefrontal parvalbumin interneurons shape neuronal activity to drive fear expression. Nature 505:92-96. CrossRef Medline

Cruikshank SJ, Lewis TJ, Connors BW (2007) Synaptic basis for intense thalamocortical activation of feedforward inhibitory cells in neocortex. Nat Neurosci 10:462-468. CrossRef Medline

Cruikshank SJ, Urabe H, Nurmikko AV, Connors BW (2010) Pathwayspecific feedforward circuits between thalamus and neocortex revealed by selective optical stimulation of axons. Neuron 65:230-245. CrossRef Medline

Cruikshank SJ, Ahmed OJ, Stevens TR, Patrick SL, Gonzalez AN, Elmaleh M, Connors BW (2012) Thalamic control of layer 1 circuits in prefrontal cortex. J Neurosci 32:17813-17823. CrossRef Medline

Delevich K, Tucciarone J, Huang ZJ, Li B (2015) The mediodorsal thalamus drives feedforward inhibition in the anterior cingulate cortex via parvalbumin interneurons. J Neurosci 35:5743-5753. CrossRef Medline

Dilgen J, Tejeda HA, O’Donnell P (2013) Amygdala inputs drive feedforward inhibition in the medial prefrontal cortex. J Neurophysiol 110: 221-229. CrossRef Medline

Euston DR, Gruber AJ, McNaughton BL (2012) The role of medial prefrontal cortex in memory and decision making. Neuron 76:1057-1070. CrossRef Medline
Felix-Ortiz AC, Burgos-Robles A, Bhagat ND, Leppla CA, Tye KM (2016) Bidirectional modulation of anxiety-related and social behaviors by amygdala projections to the medial prefrontal cortex. Neuroscience 321: 197-209. CrossRef Medline

Fino E, Yuste R (2011) Dense inhibitory connectivity in neocortex. Neuron 69:1188-1203. CrossRef Medline

Floresco SB, Tse MT (2007) Dopaminergic regulation of inhibitory and excitatory transmission in the basolateral amygdala-prefrontal cortical pathway. J Neurosci 27:2045-2057. CrossRef Medline

Fu Y, Tucciarone JM, Espinosa JS, Sheng N, Darcy DP, Nicoll RA, Huang ZJ, Stryker MP (2014) A cortical circuit for gain control by behavioral state. Cell 156:1139-1152. CrossRef Medline

Gabbott PL, Warner TA, Jays PR, Salway P, Busby SJ (2005) Prefrontal cortex in the rat: projections to subcortical autonomic, motor, and limbic centers. J Comp Neurol 492:145-177. CrossRef Medline

Gabbott PL, Warner TA, BusbySJ (2006) Amygdala input monosynaptically innervates parvalbumin immunoreactive local circuit neurons in rat medial prefrontal cortex. Neuroscience 139:1039-1048. CrossRef Medline

Gabernet L, Jadhav SP, Feldman DE, Carandini M, Scanziani M (2005) Somatosensory integration controlled by dynamic thalamocortical feedforward inhibition. Neuron 48:315-327. CrossRef Medline

Gibson JR, Beierlein M, Connors BW (1999) Two networks of electrically coupled inhibitory neurons in neocortex. Nature 402:75-79. CrossRef Medline

Groenewegen HJ, Uylings HB (2000) The prefrontal cortex and the integration of sensory, limbic and autonomic information. Prog Brain Res 126: 3-28. CrossRef Medline

Herry C, Ciocchi S, Senn V, Demmou L, Müller C, Lüthi A (2008) Switching on and off fear by distinct neuronal circuits. Nature 454:600-606. CrossRef Medline

Hippenmeyer S, Vrieseling E, Sigrist M, Portmann T, Laengle C, Ladle DR, Arber S (2005) A developmental switch in the response of DRG neurons to ETS transcription factor signaling. PLoS Biol 3:e159. CrossRef Medline

Hirai Y, Morishima M, Karube F, Kawaguchi Y (2012) Specialized cortical subnetworks differentially connect frontal cortex to parahippocampal areas. J Neurosci 32:1898-1913. CrossRef Medline

Hoover WB, Vertes RP (2007) Anatomical analysis of afferent projections to the medial prefrontal cortex in the rat. Brain Struct Funct 212:149-179. CrossRef Medline

Hull C, Isaacson JS, Scanziani M (2009) Postsynaptic mechanisms govern the differential excitation of cortical neurons by thalamic inputs. J Neurosci 29:9127-9136. CrossRef Medline

Isaacson JS, Scanziani M (2011) How inhibition shapes cortical activity. Neuron 72:231-243. CrossRef Medline

Jiang X, Wang G, Lee AJ, Stornetta RL, Zhu JJ (2013) The organization of two new cortical interneuronal circuits. Nat Neurosci 16:210-218. CrossRef Medline

Kapfer C, Glickfeld LL, Atallah BV, Scanziani M (2007) Supralinear increase of recurrent inhibition during sparse activity in the somatosensory cortex. Nat Neurosci 10:743-753. CrossRef Medline

Karalis N, Dejean C, Chaudun F, Khoder S, Rozeske RR, Wurtz H, Bagur S, Benchenane K, Sirota A, Courtin J, Herry C (2016) 4-Hz oscillations synchronize prefrontal-amygdala circuits during fear behavior. Nat Neurosci 4:605-612. CrossRef Medline

Kawaguchi Y, Kubota Y (1997) GABAergic cell subtypes and their synaptic connections in rat frontal cortex. Cereb Cortex 7:476-486. CrossRef Medline

Kawaguchi Y, Kubota Y (1998) Neurochemical features and synaptic connections of large physiologically-identified GABAergic cells in the rat frontal cortex. Neuroscience 85:677-701. CrossRef Medline

Kvitsiani D, Ranade S, Hangya B, Taniguchi H, Huang JZ, Kepecs A (2013) Distinct behavioural and network correlates of two interneuron types in prefrontal cortex. Nature 498:363-366. CrossRef Medline

Laviolette SR, Lipski WJ, Grace AA (2005) A subpopulation of neurons in the medial prefrontal cortex encodes emotional learning with burst and frequency codes through a dopamine D4 receptor-dependent basolateral amygdala input. J Neurosci 25:6066-6075. CrossRef Medline

Lee AT, Gee SM, Vogt D, Patel T, Rubenstein JL, Sohal VS (2014) Pyramidal neurons in prefrontal cortex receive subtype-specific forms of excitation and inhibition. Neuron 81:61-68. CrossRef Medline

Lee S, Kruglikov I, Huang ZJ, Fishell G, Rudy B (2013) A disinhibitory cir- 
cuit mediates motor integration in the somatosensory cortex. Nat Neurosci 16:1662-1670. CrossRef Medline

Letzkus JJ, Wolff SB, Meyer EM, Tovote P, Courtin J, Herry C, Lüthi A (2011) A disinhibitory microcircuit for associative fear learning in the auditory cortex. Nature 480:331-335. CrossRef Medline

Levy RB, Reyes AD (2012) Spatial profile of excitatory and inhibitory synaptic connectivity in mouse primary auditory cortex. J Neurosci 32: 5609-5619. CrossRef Medline

Likhtik E, Stujenske JM, Topiwala MA, Harris AZ, Gordon JA (2014) Prefrontal entrainment of amygdala activity signals safety in learned fear and innate anxiety. Nat Neurosci 17:106-113. CrossRef Medline

Little JP, Carter AG (2012) Subcellular synaptic connectivity of layer 2 pyramidal neurons in the medial prefrontal cortex. J Neurosci 32:1280812819. CrossRef Medline

Little JP, Carter AG (2013) Synaptic mechanisms underlying strong reciprocal connectivity between the medial prefrontal cortex and basolateral amygdala. J Neurosci 33:15333-15342. CrossRef Medline

Ma Y, Hu H, Berrebi AS, Mathers PH, Agmon A (2006) Distinct subtypes of somatostatin-containing neocortical interneurons revealed in transgenic mice. J Neurosci 26:5069-5082. CrossRef Medline

MacAskill AF, Cassel JM, Carter AG (2014) Cocaine exposure reorganizes cell type- and input-specific connectivity in the nucleus accumbens. Nat Neurosci 17:1198-1207. CrossRef Medline

Madisen L, Zwingman TA, Sunkin SM, Oh SW, Zariwala HA, Gu H, Ng LL, Palmiter RD, Hawrylycz MJ, Jones AR, Lein ES, Zeng H (2010) A robust and high-throughput Cre reporting and characterization system for the whole mouse brain. Nat Neurosci 13:133-140. CrossRef Medline

Mao T, Kusefoglu D, Hooks BM, Huber D, Petreanu L, Svoboda K (2011) Long-range neuronal circuits underlying the interaction between sensory and motor cortex. Neuron 72:111-123. CrossRef Medline

Markram H, Toledo-Rodriguez M, Wang Y, Gupta A, Silberberg G, Wu C (2004) Interneurons of the neocortical inhibitory system. Nat Rev Neurosci 5:793-807. CrossRef Medline

Marlin JJ, Carter AG (2014) GABA-A receptor inhibition of local calcium signaling in spines and dendrites. J Neurosci 34:15898-15911. CrossRef Medline

McGarry LM, Packer AM, Fino E, Nikolenko V, Sippy T, Yuste R (2010) Quantitative classification of somatostatin-positive neocortical interneurons identifies three interneuron subtypes. Front Neural Circuits 4:12. CrossRef Medline

Morishima M, Morita K, Kubota Y, Kawaguchi Y (2011) Highly differentiated projection-specific cortical subnetworks. J Neurosci 31:1038010391. CrossRef Medline

Otsuka T, Kawaguchi Y (2011) Cell diversity and connection specificity between callosal projection neurons in the frontal cortex. J Neurosci 31: 3862-3870. CrossRef Medline

Packer AM, Yuste R (2011) Dense, unspecific connectivity of neocortical parvalbumin-positive interneurons: a canonical microcircuit for inhibition? J Neurosci 31:13260-13271. CrossRef Medline

Packer AM, McConnell DJ, Fino E, Yuste R (2013) Axo-dendritic overlap and laminar projection can explain interneuron connectivity to pyramidal cells. Cereb Cortex 23:2790-2802. CrossRef Medline

Petreanu L, Huber D, Sobczyk A, Svoboda K (2007) Channelrhodopsin-2assisted circuit mapping of long-range callosal projections. Nat Neurosci 10:663-668. CrossRef Medline

Petreanu L, Mao T, Sternson SM, Svoboda K (2009) The subcellular organization of neocortical excitatory connections. Nature 457:1142-1145. CrossRef Medline

Pfeffer CK, Xue M, He M, Huang ZJ, Scanziani M (2013) Inhibition of inhibition in visual cortex: the logic of connections between molecularly distinct interneurons. Nat Neurosci 16:1068-1076. CrossRef Medline

Pi HJ, Hangya B, Kvitsiani D, Sanders JI, Huang ZJ, Kepecs A (2013) Cortical interneurons that specialize in disinhibitory control. Nature 503: 521-524. CrossRef Medline

Porter JT, Johnson CK, Agmon A (2001) Diverse types of interneurons generate thalamus-evoked feedforward inhibition in the mouse barrel cortex. J Neurosci 21:2699-2710. Medline

Pouille F, Scanziani M (2004) Routing of spike series by dynamic circuits in the hippocampus. Nature 429:717-723. CrossRef Medline
Reyes A, Lujan R, Rozov A, Burnashev N, Somogyi P, Sakmann B (1998) Target-cell-specific facilitation and depression in neocortical circuits. Nat Neurosci 1:279-285. CrossRef Medline

Rock C, Apicella AJ (2015) Callosal projections drive neuronal-specific responses in the mouse auditory cortex. J Neurosci 35:6703-6713. CrossRef Medline

Sesack SR, Deutch AY, Roth RH, Bunney BS (1989) Topographical organization of the efferent projections of the medial prefrontal cortex in the rat: an anterograde tract-tracing study with Phaseolus vulgaris leucoagglutinin. J Comp Neurol 290:213-242. CrossRef Medline

Silberberg G, Markram H (2007) Disynaptic inhibition between neocortical pyramidal cells mediated by Martinotti cells. Neuron 53:735-746. CrossRef Medline

Somogyi P (1977) A specific 'axo-axonal' interneuron in the visual cortex of the rat. Brain Res136:345-350. CrossRef Medline

Sotres-Bayon F, Quirk GJ (2010) Prefrontal control of fear: more than just extinction. Curr Opin Neurobiol 20:231-235. CrossRef Medline

Sotres-Bayon F, Sierra-Mercado D, Pardilla-Delgado E, Quirk GJ (2012) Gating of fear in prelimbic cortex by hippocampal and amygdala inputs. Neuron 76:804-812. CrossRef Medline

Sparta DR, Hovelsø N, Mason AO, Kantak PA, Ung RL, Decot HK, Stuber GD (2014) Activation of prefrontal cortical parvalbumin interneurons facilitates extinction of reward-seeking behavior. J Neurosci 34:3699-3705. CrossRef Medline

Stokes CC, Isaacson JS (2010) From dendrite to soma: dynamic routing of inhibition by complementary interneuron microcircuits in olfactory cortex. Neuron 67:452-465. CrossRef Medline

Sun QQ, Huguenard JR, Prince DA (2006) Barrel cortex microcircuits: thalamocortical feedforward inhibition in spiny stellate cells is mediated by a small number of fast-spiking interneurons. J Neurosci 26:1219-1230. CrossRef Medline

Tan Z, Hu H, Huang ZJ, Agmon A (2008) Robust but delayed thalamocortical activation of dendritic-targeting inhibitory interneurons. Proc Natl Acad Sci U S A 105:2187-2192. CrossRef Medline

Taniguchi H, He M, Wu P, Kim S, Paik R, Sugino K, Kvitsani D, Fu Y, Lu J, Lin Y, Miyoshi G, Shima Y, Fishell G, Nelson SB, Huang ZJ (2011) A resource of Cre driver lines for genetic targeting of GABAergic neurons in cerebral cortex. Neuron 71:995-1013. CrossRef Medline

Turrigiano G (2011) Too many cooks? Intrinsic and synaptic homeostatic mechanisms in cortical circuit refinement. Annu Rev Neurosci 34:89103. CrossRef Medline

Wang HX, Gao WJ (2009) Cell type-specific development of NMDA receptors in the interneurons of rat prefrontal cortex. Neuropsychopharmacology 34:2028-2040. CrossRef Medline

Wang Y, Toledo-Rodriguez M, Gupta A, Wu C, Silberberg G, Luo J, Markram $\mathrm{H}$ (2004) Anatomical, physiological and molecular properties of Martinotti cells in the somatosensory cortex of the juvenile rat. J Physiol 561: 65-90. CrossRef Medline

Wearne SL, Rodriguez A, Ehlenberger DB, Rocher AB, Henderson SC, Hof PR (2005) New techniques for imaging, digitization and analysis of three-dimensional neural morphology on multiple scales. Neuroscience 136:661-680. CrossRef Medline

Wickersham IR, Finke S, Conzelmann KK, Callaway EM (2007a) Retrograde neuronal tracing with a deletion-mutant rabies virus. Nat Methods 4:47-49. CrossRef Medline

Wickersham IR, Lyon DC, Barnard RJ, Mori T, Finke S, Conzelmann KK, Young JA, Callaway EM (2007b) Monosynaptic restriction of transsynaptic tracing from single, genetically targeted neurons. Neuron 53:639647. CrossRef Medline

Woodruff A, Xu Q, Anderson SA, Yuste R (2009) Depolarizing effect of neocortical chandelier neurons. Front Neural Circuits 3:15. CrossRef Medline

Xue M, Atallah BV, Scanziani M (2014) Equalizing excitation-inhibition ratios across visual cortical neurons. Nature 511:596-600. CrossRef Medline

Yizhar O, Fenno LE, Prigge M, Schneider F, Davidson TJ, O'Shea DJ, Sohal VS, Goshen I, Finkelstein J, Paz JT, Stehfest K, Fudim R, Ramakrishnan C, Huguenard JR, Hegemann P, Deisseroth K (2011) Neocortical excitation/inhibition balance in information processing and social dysfunction. Nature 477:171-178. CrossRef Medline

Zucker RS, Regehr WG (2002) Short-term synaptic plasticity. Annu Rev Physiol 64:355-405. CrossRef Medline 